\title{
RESEARCH
}

Open Access

\section{Peripheral administration of human recombinant ApoJ/clusterin modulates brain beta-amyloid levels in APP23 mice}

Sofía Fernández de Retana ${ }^{1}$, Paula Marazuela', Montse Solé ${ }^{1}$, Guillem Colell ${ }^{1}$, Anna Bonaterra', Jose Luis Sánchez-Quesada ${ }^{2,3}$, Joan Montaner', Daniel Maspoch ${ }^{4,5}$, Mary Cano-Sarabia ${ }^{4,5}$ and Mar Hernández-Guillamon ${ }^{1 *}$

\begin{abstract}
Background: ApoJ/clusterin is a multifunctional protein highly expressed in the brain. The implication of ApoJ in $\beta$ amyloid (AB) fibrillization and clearance in the context of Alzheimer's disease has been widely studied, although the source and concentration of ApoJ that promotes or inhibits $A \beta$ cerebral accumulation is not clear yet. ApoJ is abundant in plasma and approximately $20 \%$ can appear bound to HDL-particles. In this regard, the impact of plasmatic ApoJ and its lipidation status on cerebral $\beta$-amyloidosis is still not known. Hence, our main objective was to study the effect of a peripheral increase of free ApoJ or reconstituted HDL particles containing ApoJ in an experimental model of cerebral $\beta$ amyloidosis.

Methods: Fourteen-month-old APP23 transgenic mice were subjected to subchronic intravenous treatment with rHDLrApoJ nanodiscs or free rApoJ for 1 month. A $\beta$ concentration and distribution in the brain, as well as A $\beta$ levels in plasma and CSF, were determined after treatments. Other features associated to AD pathology, such as neuronal loss and neuroinflammation, were also evaluated.

Results: Both ApoJ-based treatments prevented the $A \beta$ accumulation in cerebral arteries and induced a decrease in total brain insoluble $A \beta_{42}$ levels. The peripheral treatment with rApoJ also induced an increase in the $A \beta_{40}$ levels in CSF, whereas the concentration remained unaltered in plasma. At all the endpoints studied, the lipidation of rApoJ did not enhance the protective properties of free rApoJ. The effects obtained after subchronic treatment with free rApoJ were accompanied by a reduction in hippocampal neuronal loss and an enhancement of the expression of a phagocytic marker in microglial cells surrounding $A \beta$ deposits. Finally, despite the activation of this phagocytic phenotype, treatments did not induce a global neuroinflammatory status. In fact, free $\mathrm{rApoJ}$ treatment was able to reduce the levels of interleukin-17 (IL17) and keratinocyte chemoattractant (KC) chemokine in the brain.

Conclusions: Our results demonstrate that an increase in circulating human rApoJ induces a reduction of insoluble $A \beta$ and CAA load in the brain of APP23 mice. Thus, our study suggests that peripheral interventions, based on treatments with multifunctional physiological chaperones, offer therapeutic opportunities to regulate the cerebral A $\beta$ load.
\end{abstract}

Keywords: Clusterin, Apolipoprotein J, ApoJ, APP23, Reconstituted HDL, Alzheimer's disease

\footnotetext{
*Correspondence: Mar.hernandez.guillamon@vhir.org

${ }^{1}$ Neurovascular Research Laboratory, Vall d'Hebron Research Institute,

Universitat Autònoma de Barcelona, 08035 Barcelona, Spain

Full list of author information is available at the end of the article
}

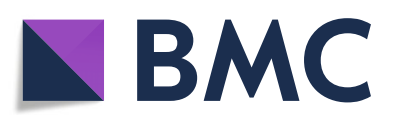

(c) The Author(s). 2019 Open Access This article is distributed under the terms of the Creative Commons Attribution 4.0 International License (http://creativecommons.org/licenses/by/4.0/), which permits unrestricted use, distribution, and reproduction in any medium, provided you give appropriate credit to the original author(s) and the source, provide a link to the Creative Commons license, and indicate if changes were made. The Creative Commons Public Domain Dedication waiver (http://creativecommons.org/publicdomain/zero/1.0/) applies to the data made available in this article, unless otherwise stated. 


\section{Background}

Cerebral $\beta$-amyloidosis is characterized by the accumulation of $\beta$-amyloid $(A \beta)$ protein in the brain parenchyma and in cerebral vessels, which are major features of Alzheimer's disease (AD) and cerebral amyloid angiopathy (CAA), respectively $[1,2]$. Both diseases are characterized by devastating clinical presentations together with a high prevalence in the elderly population. In this sense, $\mathrm{AD}$ is the first cause of dementia affecting 24 million people worldwide $[3,4]$. AD patients show severe $\beta$-amyloidosis characterized by the presence of parenchymal $A \beta$ deposits, together with intracellular accumulation of hyperphosphorylated TAU protein (neurofibrillary tangles) triggering neuroinflammation, neurodegeneration, and dementia [2]. $\mathrm{CAA}$, on the other hand, is characterized by $\mathrm{A} \beta$ deposition in brain vessels causing dementia and being the leading cause of lobar intracerebral hemorrhage ( $\mathrm{ICH}$ ) in the elderly population [5]. The $A \beta$ peptide is the product of the amyloid precursor protein (APP) processed by $\beta$ - and $\gamma$-secretases, giving rise to peptides of different lengths, including $A \beta_{40}$ and $A \beta_{42}$, which are the most interesting forms from a clinical point of view. Although both $A \beta$ peptides are prone to aggregate-forming amyloid fibrils that deposit in the brain, $A \beta_{42}$ preferentially deposits in the parenchyma (forming neuritic plaques), whereas $A \beta_{40}$ is more commonly associated with CAA-affected vessels [6, 7].

The underlying mechanisms explaining pathological $A \beta$ accumulation in the brain are not completely clear. Defective routes of $A \beta$ elimination have been proposed as an important factor leading to sporadic cerebral $\beta$-amyloidosis [8]. In this context, the most relevant $A \beta$ clearance pathways described to date include proteolytic degradation by extracellular proteases, such as insulin-degrading enzyme (IDE) and neprilysin (NEP) [9]; clearance across the blood-brain barrier (BBB) by binding to specific receptors, such as LRP-1 and LRP-2, among others [10]; and through perivascular drainage [11], promoting the mobilization of $\mathrm{A} \beta$ material along the basement membrane of cerebral arteries and capillaries to the cervical lymph nodes for its elimination. Finally, $A \beta$ can be eliminated through glial uptake by astrocytes, microglia, and myeloid cells derived from peripheral monocytes followed by intracellular digestion [12-14]. Microglial cells are resident innate immune cells that play an important role in mediating the neuroinflammatory process in the brain and the phagocytosis of toxic species such as $\mathrm{A} \beta$ material. In this context, the importance of this dual role of microglia in cerebral $\beta$-amyloidosis is increasingly recognized [15]. At this juncture, therapeutic strategies stimulating these elimination pathways have been proposed for AD.

Certain apolipoproteins, beyond their role in lipid and cholesterol metabolism, have been shown to modulate
$\mathrm{A} \beta$ accumulation in the brain. $A P O E$ genotype is the strongest genetic risk factor for the development of sporadic cerebral $\beta$-amyloidosis $[16,17]$, and although its interaction with $A \beta$ is not well understood, it has been proposed that apolipoprotein $\mathrm{E}$ (ApoE) influences $A \beta$ fibrillization [18], together with its clearance across the BBB [19]. On the other hand, apolipoprotein J (ApoJ, also known as clusterin) is one of the most highly expressed apolipoproteins in the brain after ApoE [20]. A crucial role of ApoJ in cerebral $\beta$-amyloidosis is supported by several lines of evidence, although its precise role is not well determined. ApoJ is a heterodimeric multifunctional protein. It has been described as an anti-inflammatory and antiapoptotic protein [21, 22] and a regulator of complement activation [23]. In addition, it is a very effective chaperone that is able to bind to partially misfolded proteins. In this context, ApoJ is able to bind to $A \beta$ and prevent its fibrillization [24] and toxicity in vitro [25]. In $\mathrm{AD}$ brains, ApoJ is codeposited with neuritic plaques and CAA-affected vessels, and ApoJ-A $\beta$ complexes have been detected in cerebrospinal fluid (CSF) [26]. The role of ApoJ in AD was further supported by a GWAS (genome-wide association study) that identified the $C L U$ locus as a risk factor for developing this neurological disease [27]. More revealingly, the risk factor allele $\mathrm{rs} 11136000^{\mathrm{C}}$ was associated with low expression of ApoJ, whereas the protective allele rs $11136000^{\mathrm{T}}$ caused higher ApoJ expression [28]. On the other hand, elevated circulating levels of ApoJ in plasma have been related to the severity and prevalence of $\mathrm{AD}$ [29]. This last piece of evidence suggests that an increase in ApoJ levels would occur as a protective response against the aberrant accumulation of $A \beta$ in the brain. However, there are conflicting results in the literature regarding the protective role of ApoJ. This is the case in a study showing that PDAPP mice lacking Clu (PDPP/ $\mathrm{Clu}$ ) presented reduced fibrillary $\mathrm{A} \beta$ without altering total levels of $A \beta$ [30]. On the other hand, Wojtas and colleagues observed that knocking out $\mathrm{Clu}$ in APP/PS1 mice resulted in an exacerbation of vascular $A \beta$ deposition, whereas total $A \beta$ and parenchymal $A \beta$ deposition were remarkably reduced [31]. In this sense, more recently, it has been described that the Clu deficiency in the $5 x F A D$ mouse $\mathrm{AD}$ model reduces the different $\mathrm{A} \beta$ pools only in young mice, although this effect disappears with age [32]. Nevertheless, the impact of increasing ApoJ in the circulation and/or in the brain still needs to be clarified.

From this background, our main objective was to understand the role of ApoJ in the development and progression of cerebral $\beta$-amyloidosis by determining the potential effect of ApoJ-based therapies in an experimental model of AD. Because ApoJ is present in plasma as free/nonlipidated form or associated with HDL 
(high-density lipoproteins) particles (20\% of circulating ApoJ) [33], we also analyzed whether lipidation of ApoJ could induce functional modifications associated with $\mathrm{A} \beta$ distribution in the brain. For this purpose, we analyzed the effect of peripheral administration of human recombinant ApoJ (h-rApoJ) in nonlipidated (free rApoJ) and lipidated (reconstituted HDL nanodiscs formulated with rApoJ, rHDL-rApoJ nanodiscs) [34] structural states, in terms of cerebral $A \beta$ accumulation, neuronal loss, and neuroinflammation in aged APP23 transgenic mice.

\section{Methods}

\section{Human recombinant ApoJ}

The production of functional human recombinant ApoJ (rApoJ) has been previously reported by our group [34, 35]. Briefly, human embryonic kidney $293 \mathrm{~T}$ cells (HEK293T) were transfected with the pcDNA4.0 ${ }^{\text {TM }}$ vector containing the human APOJ cDNA (Abgent, Clairemont, San Diego, USA). Stable transfected cells were grown in HYPERFlask systems (Corning Inc., New York, USA) followed by the recollection of cell supernatants for protein purification with $\mathrm{Ni}$-affinity chromatography with fast protein liquid chromatography (FLPC; AKTA Purifier 100 system, GE Healthcare Bio-Sciences Corp., Piscataway, NJ, USA) in HiScreen Ni FF columns (GE Healthcare). The purified protein was dialyzed overnight $(\mathrm{ON})$ at $4{ }^{\circ} \mathrm{C}$ against tris buffer saline (TBS) in $10 \mathrm{KDa}$ SnakeSkin Dialysis Tubing membranes (Thermo Fisher, Waltham, MA, USA). We confirmed that the produced human rApoJ was a mature-secreted protein formed as a heterodimeric complex of two $40-45 \mathrm{kDa}$ subunits [34]. For those batches intended to the preparation of reconstituted HDL particles, the resulting purified $\mathrm{rApoJ}$ was dialyzed against TBS ( $\mathrm{pH}=6.4$ ). Finally, the protein concentration was determined by BCA assay (Thermo Fisher) and diluted to a final rApoJ concentration of $200 \mu \mathrm{g} / \mathrm{ml}$ in PBS. Aliquots were stored at $-80^{\circ} \mathrm{C}$ until its usage.

\section{Preparation and purification of rHDL-rApoJ nanodiscs}

A detailed protocol for the preparation and purification of reconstituted HDL nanodiscs formulated with rApoJ (rHDL-rApoJ nanodiscs) has been previously published by our group [34]. Briefly, the process started with lipid mixture preparation with 1,2-dimyristoyl-sn-glycero-3-phosphocholine (DMPC, Avanti Polar Lipids, Alabaster, AL, USA) and free cholesterol (CHOL, Sigma-Aldrich, Saint Louis, MO, USA) in chloroform solution (5:1 DMPC:CHOL molar ratio). The organic solvent was removed under vacuum and nitrogen to afford a dry lipid film, followed by rehydration with TBS $40 \mathrm{mM}$ sodium deoxycholate (cholate, Sigma-Aldrich). This suspension was incubated $30 \mathrm{~min}$ at $37^{\circ} \mathrm{C}$ until achieving a clear solution containing the $\mathrm{DMPC} / \mathrm{CHOL} /$ cholate mixed micelles. For the preparation of rHDL-rApoJ nanodiscs, mixed micelles were incubated with free rApoJ at 550:110:1 DMPC/CHOL/rApoJ molar ratio and three incubation cycles were performed at $4{ }^{\circ} \mathrm{C}$ and $37^{\circ} \mathrm{C}$ to promote the lipid-protein interaction. After incubation, the rHDL-rApoJ nanodiscs self-assembly started with the cholate removal through extensive dialysis against 1000 -fold excess TBS at $4{ }^{\circ} \mathrm{C}$ during $48 \mathrm{~h}$ in $10 \mathrm{KDa}$ SnakeSkin Dialysis Tubing with two buffer changes $(1 \times$ $10^{9}$ overall dilution factor). Finally, dialyzed samples were centrifuged at $16000 \times g$ for $30 \mathrm{~min}$ at $4{ }^{\circ} \mathrm{C}$ to eliminate the unbound lipids. A purification step with potassium bromide (KBr; Sigma Aldrich) density gradient ultracentrifugation was needed to allow the elimination of unbound free rApoJ. This step $(100,000 \times g ; 24 \mathrm{~h}, 1250$ $\mathrm{mg} / \mathrm{ml}$ density of $\mathrm{KBr}$ ), allowed the recollection of purified rHDL-rApoJ in the upper fractions $(<1250 \mathrm{mg} / \mathrm{ml}$ density). These samples were dialyzed against PBS-2\% sucrose to eliminate $\mathrm{KBr}$. The protein concentration was determined by BCA (Thermo Scientific). rHDL-rApoJ containing solutions were diluted in PBS to a final rApoJ concentration of $200 \mu \mathrm{g} / \mathrm{ml}$, and aliquots were stored at $-80^{\circ} \mathrm{C}$ until its usage.

\section{Subchronic in vivo administration of rHDL-rApoJ nanodiscs and free rApoJ}

Mice were housed in a climate-controlled environment on a 12/12-h light/dark cycle with food and water available ad libitum. The effect of the subchronic administration of both rHDL-rApoJ nanodiscs and free rApoJ was studied in male APP23 transgenic mice (Hemizygote B6, D2-TgN[Thy-APPSWE]-23-Tg mice, Novartis, Basel, Switzerland) [36]. Male APP23 mice were used in order to diminish variation in age-related $A \beta$ deposit quantification, since male and female APP23 mice differ in the age at which $\mathrm{A} \beta$ deposition begins. These transgenic mice overexpress the APP protein with the Swedish mutation (K670M/ N671L) under the murine neuronal Thy1 promoter (thymocyte antigen-1). Hemizygous APP23 mice were backcrossed with C57BL/6 mice (Janvier Labs, Le Genest-Saint-Isle, France), and the APP genotype was tested in the offspring by Transnetyx (Cordova, TN, USA). Wild-type (wt) and APP23 mice were aged in the animal facility of our institution to obtain the final study cohort. APP23 mice received 8 intravenous (IV) doses of rHDL-rApoJ or free rApoJ (1 mg/ $\mathrm{kg}$ of $\mathrm{rApoJ})$ or saline for 4 weeks (2 doses/week). The age (mean $\pm \mathrm{SD})$ at the beginning of the treatment for each APP23 group was $14.00 \pm 0.73$ months old for the saline-treated mice $(N=7), 14.07 \pm 0.75$ months old for the rHDL-rApoJ-treated mice $(N=7)$ and $13.99 \pm 0.47$ months old for the free rApoJ-treated mice $(N=7)$. For the administration of treatments, mice were anesthetized with isoflurane $(5 \%$ for induction and $2 \%$ for maintenance in medicinal air/oxygen, Abbot Laboratories, Spain) followed by 
retro-orbital sinus injection, selected as a reliable administration route for IV delivery [37]. All animals completed the treatment, which was not associated with mortality or body weight loss. All assays conducted in mouse brains after treatment were evaluated in a blinded manner.

\section{Cerebrospinal fluid collection}

Thirty minutes after the last administration, mice were anesthetized under isoflurane and CSF was sampled as previously described [38]. Briefly, anesthetized mice were placed in the stereotaxic instrument and a sagittal section inferior of the occiput was done in the skin. Once the dura mater of the cistern magna was visualized under the microscope, it was penetrated with a glass capillary (inner diameter of $0.5 \mathrm{~mm}$ ) and clear CSF ascended by capillarity. Only completely clear CSF was considered for further experiments.

\section{Blood and brain collection}

Blood was collected through cardiac puncture, and blood samples were centrifuged in ethylenediaminetetracetic acid (EDTA) tubes to recollect the EDTA-plasma. Then, after transcardial perfusion with $25 \mathrm{ml}$ of cold PBS $(\mathrm{pH}=7.4)$, brains were rapidly removed and divided into two hemispheres. One of the hemispheres was frozen at $-80{ }^{\circ} \mathrm{C}$ for homogenization, while the other was fixed in $10 \%$ formalin (Diapath, Martinengo, Italy) at room temperature (RT) for $48 \mathrm{~h}$ before paraffin embedding.

\section{Brain homogenates}

One of the hemispheres of each mouse was homogenized to obtain soluble, membrane-associated, and insoluble fractions through sequential centrifugations. First, the brain tissue was homogenized in $4 \mathrm{ml}$ of TBS $(\mathrm{pH}=7.4)$ supplemented with cOmplete EDTA-free protease inhibitor cocktail (Roche Diagnostic, Mannheim, Germany) and samples were centrifuged at $8000 \times g$ for $30 \mathrm{~min}$ a $4{ }^{\circ} \mathrm{C}$. The supernatant was selected as the soluble fraction whereas the pellet was homogenized in TBS supplemented with TritonX-100 and protease inhibitors followed by centrifugation at $8000 \times g$ for $30 \mathrm{~min}$ at $4{ }^{\circ} \mathrm{C}$. The supernatant was selected as the membrane-bound fraction whereas the pellet was homogenized in $5 \mathrm{M}$ guanidine- $\mathrm{HCl}(\mathrm{pH}=8$, Sigma-Aldrich) supplemented with protease inhibitors. Samples were shaken for $3 \mathrm{~h}$ at RT followed by centrifugation at $8000 \times g$ for 30 $\min$ at $4{ }^{\circ} \mathrm{C}$, and the supernatant was selected as the insoluble fraction. Soluble, membrane-bound, and insoluble fractions were aliquoted and frozen at $-80^{\circ} \mathrm{C}$. The protein concentration of each fraction was quantified by BCA assay (Thermo Fisher).

\section{Enzyme-linked immunosorbent assay (ELISA)}

A $\beta$ levels in plasma, CSF, and soluble and insoluble brain fractions were quantified with commercial ELISA kits for both $A \beta_{40}$ (KHB3481) and $A \beta_{42}$ (KHB2442, Thermo Fisher). Levels of human ApoJ in plasma of treated mice were quantified with the commercial ELISA kit (3713-1HP, Mabtech, Nacka Strand, Sweden). Levels of the endogenous mouse ApoJ in brain homogenates and plasma in APP23 mice were determined using the mouse Clusterin ELISA Kit (ab199079, Abcam, Cambridge, UK). Commercially available multiplexed ELISA was used to investigate the general inflammatory state in brain soluble fraction after treatments (Mouse cytokine magnetic 20-plex panel, LMC0006M, Invitrogen). Results were analyzed in duplicate with Luminex technology in a MAGPIX ${ }^{\mathrm{Tm}}$ instrument, and samples with a coefficient of variation $(\mathrm{CV})>35 \%$ were excluded. In all cases, data were corrected by the amount of total protein determined by BCA.

\section{Immunohistochemistry}

A series of three paraffin-embedded sagittal sections were selected $800 \mu \mathrm{m}$ apart, starting from the division between the hemispheres. For the detection of $A \beta$ with conventional immunohistochemistry (IHC), all samples were deparaffinized for $1 \mathrm{~h}$ at $65^{\circ} \mathrm{C}$, rehydrated, and treated with $2 \% \mathrm{H}_{2} \mathrm{O}_{2}$ and $10 \%$ methanol in PBS for 15 min. The samples were incubated for $1 \mathrm{~h}$ in blocking solution (PBS, $0.2 \%$ Triton-X, 10\% fetal bovine serum (FBS, Millipore, Darmstadt, Germany) followed by ON incubation with the anti-A $\beta$ monoclonal antibody $4 \mathrm{G} 8$ (BioLegend, San Diego, CA, USA) diluted 1:10000 in blocking solution. Next, slices were incubated with biotinylated anti-mouse IgG (Vector Laboratories, Burlingame, CA, USA) diluted 1:200 in blocking solution for 1 $\mathrm{h}$ at RT and with streptavidin-HRP (Vector Laboratories) diluted 1:200 in blocking solution for $1 \mathrm{~h}$ at RT. Finally, diaminobenzidine (DAB; Dako, Denmark) was applied to the samples until a brown end-product was observed. Contrast staining was performed by immersion of the samples in Harris hematoxylin solution (Sigma-Aldrich). To quantify the number of $A \beta$-positive deposits, we used the overview tool of a Leica LMD 6500 Laser Microdissection Microscope System to scan each brain slice in full. Overview images were labeled with codes to ensure blind quantification. The number of $\mathrm{A} \beta$ deposits larger than $50 \mathrm{px}^{2}$ in the cortex and the area $\left(\mathrm{px}^{2}\right)$ occupied per deposit were quantified with ImageJ software. Three different deep sections per brain were analyzed, and a mean of the values determined in those sections was obtained. Data are expressed as the number of $A \beta$-positive deposits per total area $\left(\mathrm{px}^{2}\right)$ and the mean size of those $\mathrm{A} \beta$-positive deposits. Representative images were obtained with a conventional microscope (BX61, Olympus, Tokyo, Japan).

An immunohistochemistry protocol was also performed for the quantification of NeuN-positive cells in 
the cortex and hippocampus (CA1, CA2/CA3, and polymorphic layer of dentate gyrus (poDG)) of APP23 and age-matched wt mice in the first deep-section slice. Before the blocking step, an antigen retrieval step was performed by immersing the slices in citrate buffer $(10 \mathrm{mM}$ sodium citrate, $0.05 \%$ TWEEN-20, $\mathrm{pH}=6)$ at $95^{\circ} \mathrm{C}$ for $30 \mathrm{~min}$. The NeuN antibody (Millipore) was diluted 1:200 in blocking solution. The quantification of NeuN-positive cells in the different areas was performed as previously described [39]. Briefly, for each sample and brain region, three different images were taken at $\times 40$ magnification using an LMD6500 microscope (Leica, Wetzlar, Germany). NeuN-positive cells were counted in three different squares in every image measuring $150 \times$ $150 \mu \mathrm{m}$ in cortical regions, whereas squares measuring $100 \times 100 \mu \mathrm{m}$ were used in hippocampal regions. The results are expressed as the number of NeuN-positive cells per square millimeter.

\section{Thioflavin S staining}

Thioflavin $\mathrm{S}$ (ThS) staining was performed to detect fibrillar $A \beta$ deposits in brain slices. After deparaffination and rehydration, a series of 3 selected sagittal sections $800 \mu \mathrm{m}$ apart were immersed in ThS (Sigma-Aldrich) 1\% solution in $75 \%$ ethanol for $30 \mathrm{~s}$. The excess of ThS was drained, and the sections were immersed in ThS $0.1 \%$ in $75 \%$ ethanol for $1 \mathrm{~min}$. Finally, the slices were dehydrated, and DAPI (4',6-diamidino-2-phenylindole) was used for counterstaining before the preparations were mounted. The number of ThS-positive deposits, the size of those deposits, and the number of ThS-positive brain vessels were quantified as previously described for the quantification of $\mathrm{A} \beta$ deposits by immunohistochemistry. The count of ThS-positive deposits larger than $50 \mathrm{px}^{2}$ and the analysis of the area $\left(\mathrm{px}^{2}\right)$ occupied per deposit were quantified with Image software. Data are expressed as the number of CAA-affected vessels (ThS-positive brain vessels), the number of ThS-positive deposits per total area $\left(\mathrm{px}^{2}\right)$ and the mean size of ThS-positive deposits. Representative images were obtained with a conventional fluorescence microscope (BX61, Olympus, Tokyo, Japan).

\section{Immunofluorescence}

A cluster of differentiation 68 (CD68) as a marker of phagocytosis and Tomato lectin (TL) as vascular and microglia marker [40] were analyzed through immunofluorescence in paraffin-embedded brain sections. To this end, after deparaffination, rehydration, and antigen retrieval with citrate buffer $(10 \mathrm{mM}$ sodium citrate, $0.05 \%$ Tween20, $\mathrm{pH}=6,30 \mathrm{~min}$ at $95^{\circ} \mathrm{C}$ ), slices were blocked in $\mathrm{PBS} \mathrm{pH}=7.4$ supplemented with $10 \% \mathrm{FBS}$ and $1 \%$ Tween 20 for $1 \mathrm{~h}$ at RT. Rabbit anti-mouse CD68 antibody (Abcam) diluted 1:50 in blocking solution was incubated $\mathrm{ON}$ at $4{ }^{\circ} \mathrm{C}$. Next, secondary antibody anti-rabbit-AlexaFluor488 (Thermo Fisher) diluted 1:500 in blocking solution was incubated $1 \mathrm{~h}$ at RT followed by incubation with Tomato lectin-DyLight564 (Vector Laboratories) diluted 1:100 in blocking solution $1 \mathrm{~h}$ at RT. On the other hand, the localization of CD68 and $A \beta$ was analyzed in paraffin-embedded brain sections. After the deparaffination and rehydration steps, brain slices were treated with $70 \%$ formic acid for 10 min followed by 3 washes of $5 \mathrm{~min}$ with PBS-1\% Tween20. Then, the samples were incubated in blocking solution for $1 \mathrm{~h}$ at RT followed by $\mathrm{ON}$ incubation at $4{ }^{\circ} \mathrm{C}$ with mouse anti-human $A \beta$ monoclonal antibody (4G8) diluted 1:1000 and rabbit anti-mouse CD68 (Abcam) diluted 1:50 or rabbit anti-Ibal (ionized calcium binding adapter molecule-1, Abcam) diluted 1:100 in blocking solution. Next, secondary antibodies anti-rabbit-AlexaFluor-488 and anti-mouse-AlexaFluor694 (Thermo Fisher) diluted 1:500 in blocking solution for $1 \mathrm{~h}$ at RT. Finally, contrast staining was done with DAPI before mounting the preparations. Images were obtained with a conventional fluorescence microscope (BX61, Olympus). Finally, human ApoJ was analyzed in brain sections of treated animals. To this end, after the rehydration, antigen retrieval, and blocking steps, brain slices were incubated $\mathrm{ON}$ with mouse-anti-human ApoJ (BD Bioscience, San Jose, CA, USA) diluted 1:100 in blocking solution. AlexaFluor-594 was used as a secondary antibody (1:500), and DAPI was used as contrast staining. Images were obtained with a confocal spectral microscopy (FV1000, Olympus).

\section{Western blot}

For the immunodetection of different protein profiles, $40 \mu \mathrm{g}$ of soluble or membrane-bound brain homogenate fractions or $1 \mu \mathrm{l}$ of mouse plasma was loaded in $10 \%$ acrylamide SDS-PAGE under reducing conditions (5\% $\beta$-mercaptoethanol and sample heating at $95^{\circ} \mathrm{C}$ ). Then, gels were transferred onto nitrocellulose membranes using Trans-Blot Turbo transfer system (Bio-Rad, Hercules, CA, USA) at $1.3 \mathrm{~A}, 25 \mathrm{~V}$ for $10 \mathrm{~min}$ and blocking was done in $10 \%$ non-fatted milk for $1 \mathrm{~h}$ at RT. Membranes were incubated in tested specific antibodies diluted in blocking solution at $4{ }^{\circ} \mathrm{C}$ ON. Suitable secondary HRP-labeled antibodies diluted in blocking solution were incubated $1 \mathrm{~h}$ at RT. The processing of membranes continued with the incubation with PierceECL Western blotting Luminol/Enhancer and Stable Peroxidase solutions (Thermo Fisher). The relative amount of the targeted protein was calculated from the quantification of the mean intensity with the ImageJ software. Immunoblotting of $\beta$-actin, $\beta$-tubulin, or glyceraldehydes 3-phosphate dehydrogenase (GADPH) was used as loading controls. The primary antibodies used were rabbit anti-CD68 (1:1000, Abcam), rabbit anti-GFAP (Glial 
Fibrillary Acidic Protein, 1:1000, Dako), rabbit anti-Iba1 (1:1000, Abcam), mouse anti-LRP1 (1:1000, Abcam), mouse anti-human APP (1:1000, Millipore), mouse anti-sAPP $\alpha$ (Soluble APP fraction- $\alpha, 1: 1000$, Clontech, Mountain View, CA, USA), mouse anti-sAPP $\beta$ (Soluble APP fraction- $\beta, 1: 1000$, Clontech), rabbit-anti RAGE (1:1000, Abcam), goat-anti-mouse ApoJ (1:1000, RD Systems, Minneapolis, MN, USA), mouse anti- $\beta$-actin (1:10000, Sigma-Aldrich) and mouse anti-GADPH (1:10000, Invitrogen). The following HRP-labeled secondary antibodies were used: Anti-rabbit-HRP (1:2000, GE Healthcare Biosciences, Little Chalfont, UK), anti-mouse-HRP (1:2000, GE Healthcare Bioscience), and anti-goat-HRP (1:5000, Sigma-Aldrich).

\section{Microglial cell cultures}

The mouse microglial cell line BV-2 was obtained from the European Collection of Authenticated Cell Culture (ECACC). BV-2 cells were seeded (30.000 cells/well) in poly-L-lysine (Sigma-Aldrich)-coated sterile coverslips in 24-well plates and incubated at $37^{\circ} \mathrm{C}$ in RPMI 1640 medium (Thermo Fisher) supplemented with $10 \%$ fetal bovine serum (FBS, Thermo Fisher) and $1 \%$ penicillin-streptomycin (Thermo Fisher) for $24 \mathrm{~h}$. For treatments, the medium was changed to RPMI containing 0.1\% FBS and cells were incubated with or without rApoJ $(0.1 \mu \mathrm{M})$ for $24 \mathrm{~h}$ as a pre-treatment. Then, rApoJ was removed by washing the wells with RPMI $0.1 \%$ FBS and $0.5 \mu \mathrm{M}$ human $\mathrm{A} \beta(1-40)$ HiLyteTM Fluor 488-labeled (AnaSpec, Fremont, CA, USA) was added for $3 \mathrm{~h}$ to the corresponding wells. Next, cells were washed twice with PBS containing $5 \%$ bovine serum albumin (BSA, Sigma-Aldrich) and fixed with $4 \%$ paraformaldehyde (PFA, Sigma-Aldrich) for $15 \mathrm{~min}$. After fixation, cells were washed twice with PBS and levels of 488-A $\beta(1-$ $40)$ in the cells were analyzed by measuring the fluorescence $(\mathrm{Ex} / \mathrm{Em}=503 / 528 \mathrm{~nm})$ using a Synergy $\mathrm{Mx}$ microplate reader (Biotek). To visualize the cellular structure, a phalloidin-tetramethylrhodamine B isothiocyanate (phalloidin-TRITC, Sigma-Aldrich) actin staining was used (50 $\mu \mathrm{g} /$ $\mathrm{ml}$ in PBS for $20 \mathrm{~min}$ ). After washing twice with PBS, the coverslips were mounted on slides using FluoroshieldTM with DAPI (Sigma-Aldrich). Images were obtained with confocal spectral microscopy (FV1000, Olympus).

\section{Statistical analysis}

GraphPad Prism 6 and SPSS Statistics 17.0 software were used for the statistical analysis. The normality of distributions was assessed with the Shapiro-Wilk normality test. The differences were assessed using a $t$ test or one-way ANOVA with an LSD (least significant difference) post hoc test when appropriate. When data did not fit a normal distribution, the Kruskal-Wallis test with a Dunn's post hoc was used for multiple comparisons, and the Mann-Whitney test was used for one-to-one comparisons. The Benjamini-Hochberg false discovery rate (FDR) correction was used to control for multiple testing in the multiplexed analysis of brain inflammatory status. A $p$ value $<0.05$ was considered statistically significant.

\section{Results}

APP23 mice are characterized by increasing accumulation of both human $A \beta_{40}$ and $A \beta_{42}$ in the brain. This rising $A \beta$ deposition became especially evident in very old APP23 mice (24 months old), where a 20 -fold increase in insoluble $A \beta_{40}$ and a 10-fold increase in insoluble $A \beta_{42}$ were observed in comparison with the corresponding $\mathrm{A} \beta$ load in 15-month-old APP23 mice (Fig. 1a, b). Interestingly, this growing $A \beta$ accumulation was accompanied by an increase in mouse ApoJ (m-ApoJ) levels in the brain (Fig. 1c). Twenty-four-month-old APP23 mice presented significantly higher m-ApoJ brain levels than age-matched wt mice, whereas the difference between genotypes was nonsignificant in 15-month-old mice. In addition, as expected, this increase in brain m-ApoJ was exacerbated with age, as significant differences in m-ApoJ levels were detected between 15- and 24-month-old APP23 mice. Plasma levels of endogenous $\mathrm{m}$-ApoJ were also determined, although no significant differences between genotypes were found in 15- or 24-month-old mice (Fig. 1d).

The endogenous increase in m-ApoJ in APP23 mice at late pathological stages could be interpreted as a physiological protective mechanism to promote reduction and clearance of $A \beta$ in the brain. In this regard, we wondered whether an earlier increase in ApoJ levels could be a beneficial strategy to delay the $A \beta$ deposition detected over time. Therefore, our main objective was to study the effect of peripheral administration of free rApoJ or lipidated rApoJ (rHDL-rApoJ nanodiscs) in APP23 mice. To this end, APP23 mice received 8 intravenous administrations (over the course of 1 month) of free rApoJ (1 $\mathrm{mg} / \mathrm{kg})$, rHDL-rApoJ $(1 \mathrm{mg} / \mathrm{kg})$, or saline, with 2 infusions/week (Fig. 2a). The administered dose of $1 \mathrm{mg} / \mathrm{kg}$ of human rApoJ would theoretically lead to a mean increase of $20 \%$ in total circulating ApoJ levels considering the $\mathrm{m}$-ApoJ levels determined in plasma. The equality of the initial amounts of infused rHDL-rApoJ and free rApoJ was confirmed by Western blot, as shown in Fig. $2 b$, where the $\alpha$ - and $\beta$-chains of rApoJ were observed at $\approx 37 \mathrm{KDa}$. Next, the circulating concentration of human rApoJ (h-rApoJ) was quantified by ELISA. A significant increase in plasma levels of h-rApoJ was observed in both rHDL-rApoJ- and free rApoJ-treated mice, whereas human ApoJ, as expected, was not detected in the saline group (Fig. 2c). In addition, no significant differences in h-ApoJ between the rHDL-rApoJand free rApoJ-treated groups were found in plasma 30 


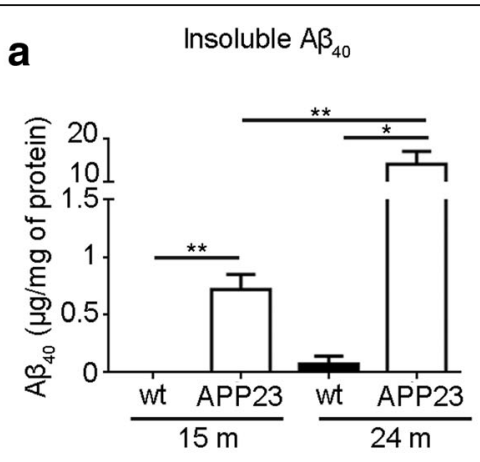

C
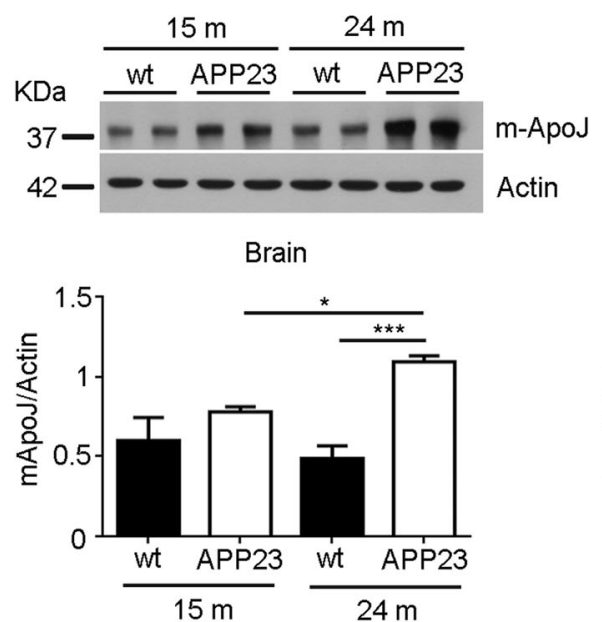

b

Insoluble $A \beta_{42}$

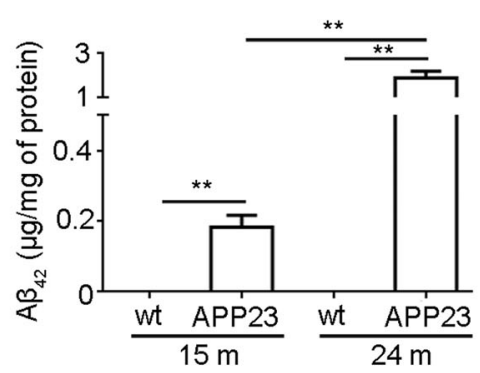

d

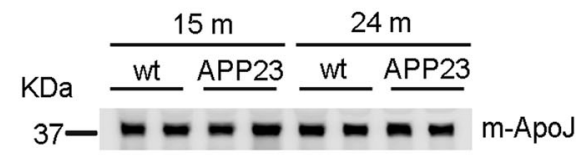

Fig. 1 Levels of cerebral insoluble $A \beta$ and mouse ApoJ expression in APP23 transgenic mice over time. a Cerebral accumulation of insoluble $A \beta_{40}$ in 15- and 24-month-old APP23 and wt mice. b Cerebral accumulation of insoluble A $\beta_{42}$ in 15- and 24-month-old APP23 and wt mice. c Mouse ApoJ (m-ApoJ) cerebral expression in 15- and 24-month-old APP23 and wt mice. d Mouse ApoJ (m-ApoJ) levels in the plasma of 15 and 24-month-old APP23 mice. Data are expressed as the mean \pm SEM. $N=3-4$ /group. ${ }^{*} p<0.05 ;{ }^{* *} p<0.01 ;{ }^{*} p<0.001$

min after administration. On the other hand, the levels of h-rApoJ in brain homogenates were undetectable by ELISA $(<70 \mathrm{pg} / \mathrm{ml}) 30 \mathrm{~min}$ after the last administration of the subchronic treatment (Fig. 2d). However, immunofluorescence analysis revealed specific staining for h-ApoJ in occasional vessels from the brains of both rHDL-rApoJ- and free rApoJ-treated mice. Brains from saline-treated mice did not present human ApoJ staining (Fig. 2e). On the other hand, h-rApoJ-based peripheral treatments did not influence the expression of $\mathrm{m}$-ApoJ in brain homogenates or $\mathrm{m}$-ApoJ levels in plasma, as detected by ELISA (Additional file 1: Figure S1).

The efficacy of subchronic rApoJ-based treatments in APP23 mice was first evaluated in terms of cerebral A $\beta$ load. Levels of $A \beta_{40}$ and $A \beta_{42}$ in soluble and insoluble fractions of brain homogenates were quantified by ELISA after the treatments (Fig. 3a-c). The levels of soluble $A \beta_{40}$ were not significantly different among treatments, although a trend towards a reduction in free rApoJ-treated mice was observed $(p=0.09)$. Soluble
$A \beta_{42}$ levels were under the lower limit of detection $(<6$ $\mathrm{pg} / \mathrm{ml}$ ). Interestingly, we observed lower levels of both insoluble $A \beta_{40}$ and $A \beta_{42}$ in mice treated with free $\mathrm{rApoJ}$ than in the saline-treated group (insoluble $A \beta_{40} 1.01 \pm$ 0.12 vs. $2.70 \pm 0.44 \mu \mathrm{g} / \mathrm{mg}$ and insoluble $A \beta_{42} 0.27 \pm 0.02$ vs. $0.60 \pm 0.11 \mu \mathrm{g} / \mathrm{mg}$ in $\mathrm{rApoJ}$-treated group compared to the saline-treated group, $p<0.01$ ) (Fig. 3b, c). However, after treatment with rHDL-rApoJ nanodiscs, the insoluble $A \beta_{40}$ levels remained unaltered, whereas lower insoluble $A \beta_{42}$ brain levels were found in comparison with the saline-treated group (insoluble $A \beta_{42} 0.38 \pm 0.07$ vs. $0.60 \pm 0.11 \mu \mathrm{g} / \mathrm{mg}$ in $\mathrm{rHDL}$-treated group compared to the saline-treated group, $p<0.05$ ) (Fig. 3b, c). Regarding the cerebral $A \beta$ distribution, the number of $A \beta$-affected vessels and the number of parenchymal deposits were quantified by ThS staining and immunohistochemistry with a specific anti-A $\beta$ antibody (Fig. $3 d-f$ ). Brains from mice treated with rHDL-rApoJ and free rApoJ presented a significantly lower number of CAA-affected arteries as detected by ThS staining (the 

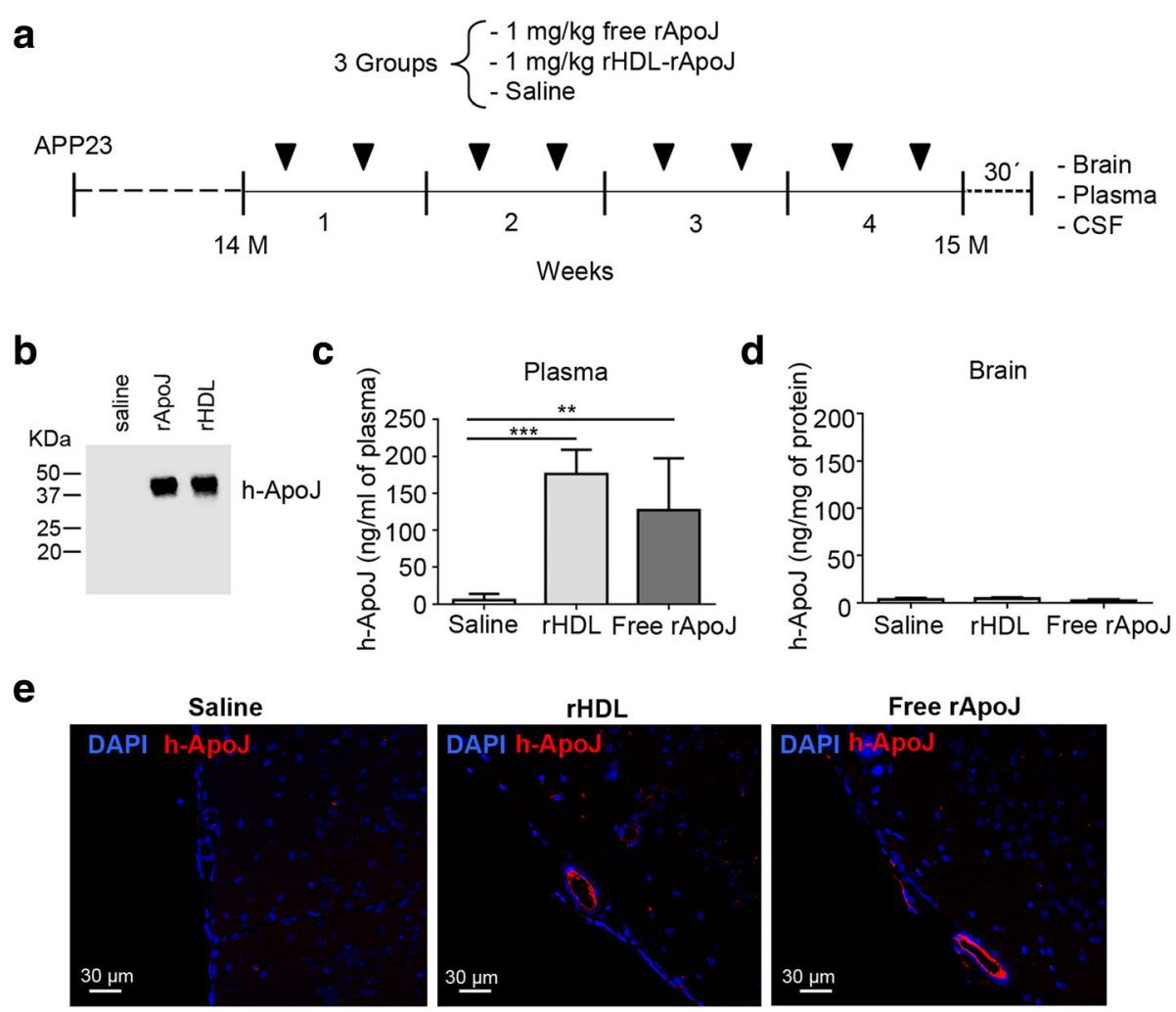

Fig. 2 Subchronic intravenous treatment of APP23 mice with human recombinant ApoJ (h-rApoJ). a Schematic timeline representing the experimental design of the study based on the subchronic administration of APP23 mice with rHDL-rApoJ nanodiscs, free rApoJ or saline. $\mathbf{b}$ Immunodetection (anti-hApoJ) of treatment samples before being intravenously infused. c Plasmatic levels of h-ApoJ in treated mice 30 min after the last administration detected by ELISA ( $N=7 /$ group). $\mathbf{d}$ Levels of h-ApoJ in brain homogenates from treated mice detected by ELISA ( $N=7 /$ group). e Immunofluorescent detection of h-ApoJ in paraffin-embedded brain sections. ${ }^{* *} p<0.01 ;{ }^{* *} p<0.001$

reduction percentages were $64.9 \%$ and $54.8 \%$ vs. saline-treated group, respectively) (Fig. 3d). Although no differences were detected in the parenchymal $A \beta$ deposition load after rApoJ-based treatments (Fig. 3e, f), the mean size of fibrillar $\mathrm{A} \beta$ accumulations (ThS-positive deposits) was reduced in those mice treated with free rApoJ (the reduction percentage in free rApoJ vs. saline-treated group was 17.5\%) (Fig. 3e). Finally, the deposition load and size of parenchymal $A \beta$ deposits did not differ significantly among groups as shown by a specific immunostaining against $A \beta$, although a clear tendency towards smaller deposits after both rApoJ-based treatments was again observed (Fig. 3f).

Neuronal loss is one of the neuropathological hallmarks in $\mathrm{AD}$ [41], and it has been described that the APP23 mice model shows a neuronal loss in the CA1 region of the hippocampus and in the poDG from 12 months of age [39]. Thus, we measured the effect of rHDL-rApoJ and free rApoJ treatments over the neurodegeneration in the cortex and hippocampus through NeuN immunostaining. In comparison with age-matched wt mice, we found that 15-month-old APP23 mice exhibited a neuronal reduction in CA1 and
poDG (Fig. 4). Importantly, the treatment with free rApoJ was able to significantly ameliorate the neuronal loss in both CA1 and poDG in comparison to the saline-treated group (Fig. 4).

Because an increase in fibrillary $A \beta$ in the brain is associated with low levels of particular $A \beta$ species in the CSF of $A D$ and CAA patients $\left(A \beta_{42}\right.$ and $A \beta_{40}$, respectively $[42,43])$, we analyzed the $A \beta$ levels in CSF $30 \mathrm{~min}$ after the last treatment in APP23 mice. We observed a significant increase in CSF $\mathrm{A} \beta_{40}$ levels in mice treated with free rApoJ compared to the rest of the groups $(17.10 \pm 1.83$ vs. $10.46 \pm 1.47 \mathrm{ng} / \mathrm{ml}$ in the saline-treated group, $p<0.01$ ) (Fig. 5a). However, $\mathrm{A} \beta_{40}$ levels in plasma were not different among groups $30 \mathrm{~min}$ after the last infusion (Fig. 5b). Circulating levels of $A \beta_{42}$ in APP23 mice were undetectable in all cases. In addition, we explored the expression of different brain receptors previously described to mediate the transport of $A \beta$ across the BBB [10]. In this context, the expression of LRP-1 or RAGE did not exhibit expression differences among groups (Fig. 5c). Moreover, we also eliminated the possibility that the decrease in insoluble $A \beta$ in the brain and the increase in CSF A $\beta$ levels obtained after peripheral 


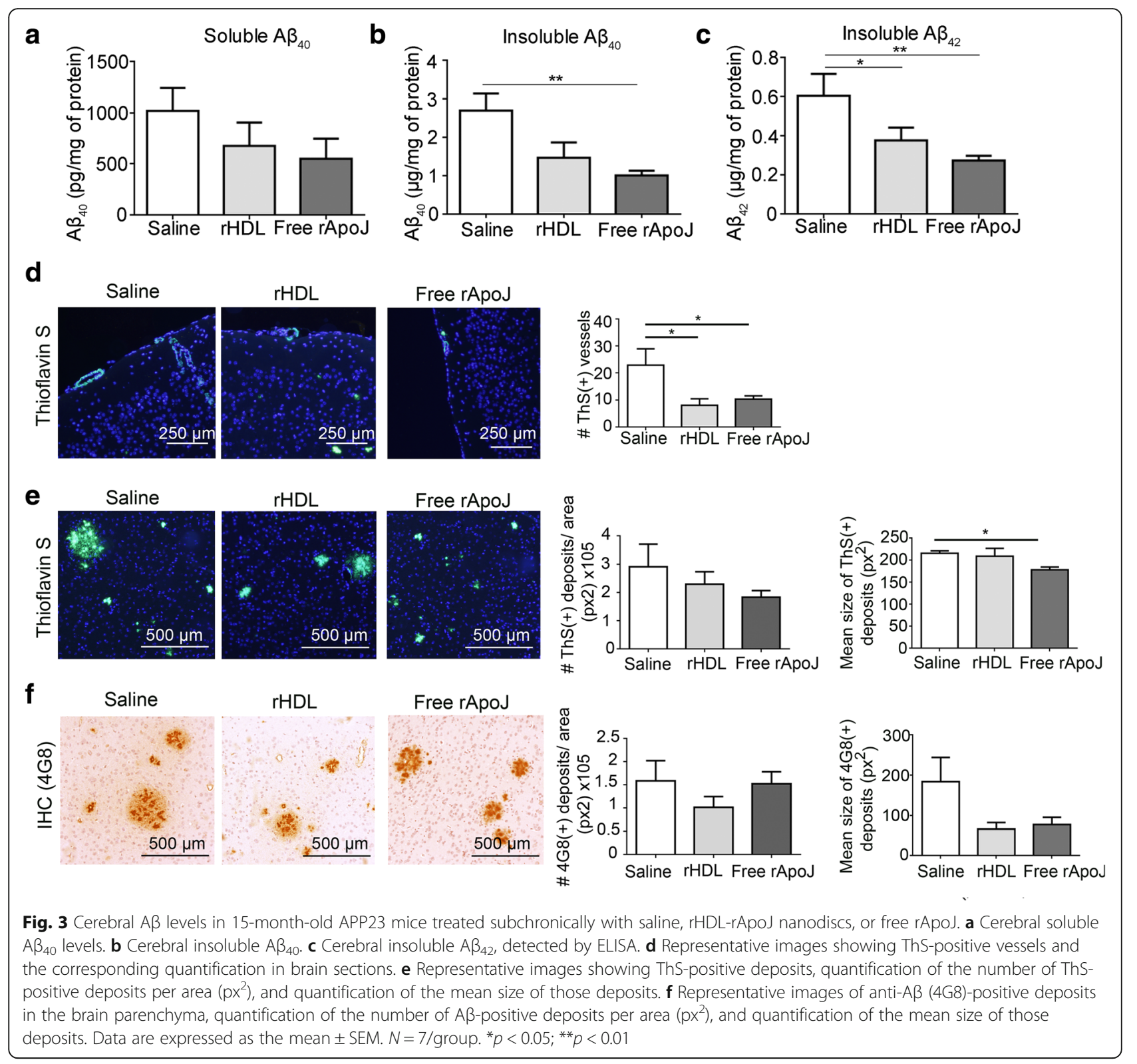

rApoJ treatment could be explained by an alteration of APP transgene expression or the A $\beta$ peptide production process. Specifically, we confirmed that the expression of APP was unaltered in the brains of mice receiving different treatments, and the processing of APP mediated by $\alpha$-secretase, $\beta$-secretase, and $\gamma$-secretase was also unchanged among groups (Additional file 1: Figure S2).

The neuroinflammatory state of mice that received ApoJ-based treatments was first analyzed by exploring the expression levels of specific cellular markers in brain homogenates. On this front, we determined that the presence of the activated astrocytic protein GFAP did not differ after treatments (Fig. 6a). On the other hand, we detected a 2.3-fold increase in the levels of the lysosomal marker CD68 in brain homogenates from free
ApoJ-treated mice $(p<0.05)$, whereas the expression of the resident microglial marker Iba-1 was not significantly different among groups (Fig. 6b). Iba1 and CD68 localization was determined by immunofluorescence, and the signal was observed in the periphery of parenchymal A $\beta$-positive deposits, showing elevated CD68 expression levels in mice treated with free rApoJ (Fig. 6c, d). Furthermore, double staining of CD68 with tomato lectin (TL) confirmed the presence of this lysosomal marker in microglial cells (Fig. 6e). Additionally, a multiplexed ELISA was performed to detect the global inflammatory state in the brain parenchyma (the complete list of molecules analyzed can be found in Additional file 1: Table S1). Despite the phagocytic phenotype shown by microglial cells after the free rApoJ treatment, we did 


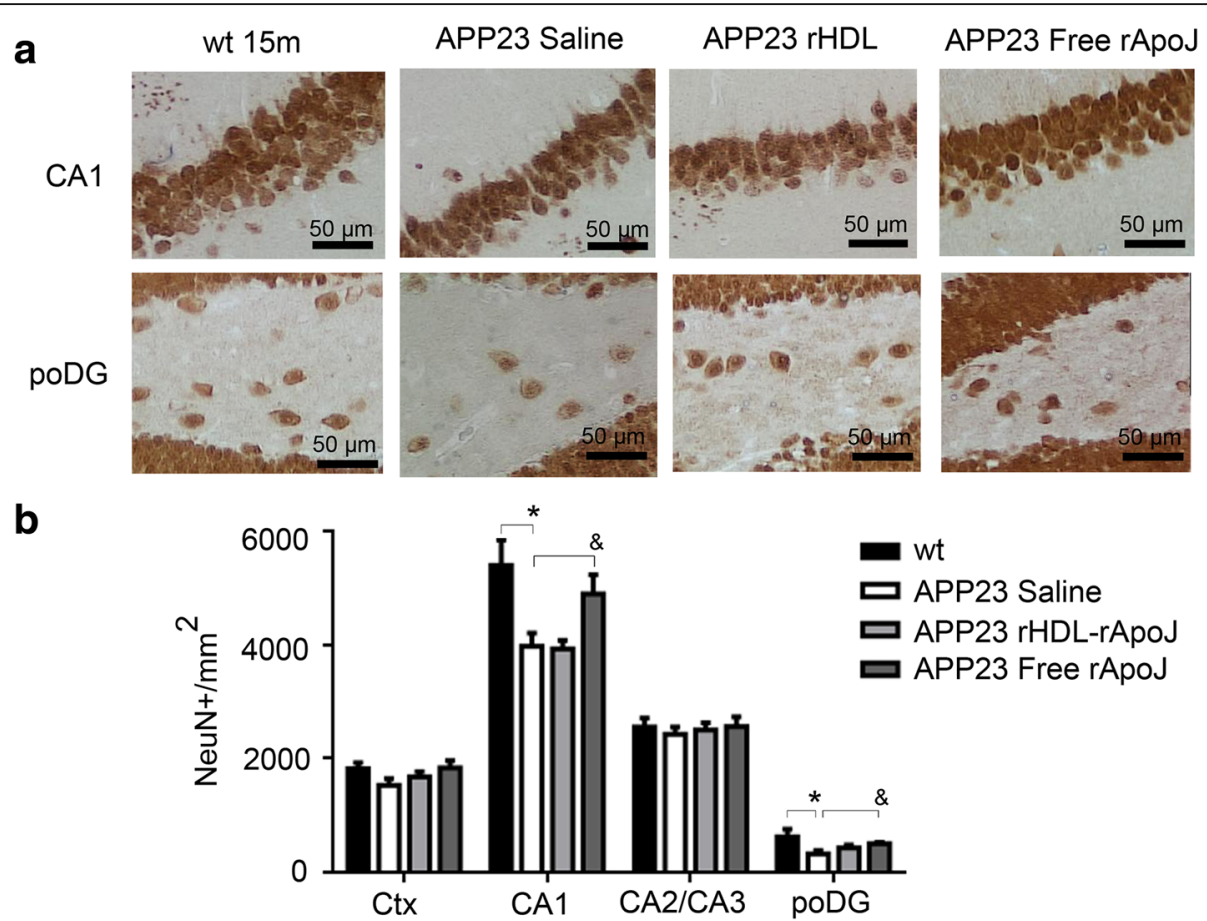

Fig. 4 Neuronal loss in 15-month-old wt mice and APP23 mice treated subchronically with saline, rHDL-rApoJ nanodiscs or free rApoJ. a Representative images of NeuN-positive cells in CA1 region of the hippocampus and in poDG of APP23-treated mice and wt mice. $\mathbf{b}$ Quantification of NeuN-positive cells per square millimeter in the different studied regions (cortex, CA1, CA2/CA3, and poDG). Abbreviations: Ctx: Cortex; poDG: polymorphic layers of the dentate gyrus. Data are expressed as the mean \pm SEM. $N=6-7 /$ group. ${ }^{*} p<0.05$ (comparison between WT and saline-APP23 groups) and $p<0.05$ (comparison among APP23-treated groups)

not observe an increase in the levels of prevalent brain cytokines and inflammatory molecules, such as the classical mediator interleukin 1- $\beta$ (IL-1 $\beta$ ) or tumor necrosis factor- $\alpha$ (TNF- $\alpha)$. In fact, we detected reduced levels of interleukin 17 (IL17) and KC (keratinocyte chemoattractant chemokine) in the brains from mice treated with both rHDL-rApoJ and free rApoJ. However, after FDR correction, only levels of IL17 and KC in free r-ApoJ-treated brains remained statistically different than the corresponding levels in the saline-treated group (Table 1).

Finally, the potential direct effect of free rApoJ on microglial phagocytic activity was tested in vitro. BV2 microglial mouse cells were pretreated with or without rApoJ $(0.1 \mu \mathrm{M})$ for $24 \mathrm{~h}$ and then incubated with HyLite Fluor 488-labeled $\mathrm{A} \beta_{40}(0.5 \mu \mathrm{M})$ for $3 \mathrm{~h}$. Confocal images revealed that rApoJ-pretreated cells retained higher fluorescent-labeled $\mathrm{A} \beta_{40}$ levels than non-pretreated cells (Fig. 7a), indicating higher $A \beta$ uptake in cells challenged with rApoJ. The presence of fluorescent-labeled $A \beta_{40}$ inside the cells was corroborated in confocal microscope z-stack images (Fig. 7b). In addition, quantification of HyLite Fluor 488-labeled $A \beta_{40}$ internalized in cultured cells was determined fluorometrically. Results confirmed that rApoJ-pretreated cells significantly enhanced the $A \beta$ phagocytic activity compared with non-pretreated cells (Fig. 7c).

\section{Discussion}

Despite the high socioeconomic impact of $\mathrm{AD}$ and CAA, these diseases lack an effective disease-modifying therapy. The involvement of ApoJ in AD is widely acknowledged, although its underlying mechanism in this pathology is not yet elucidated. Therefore, the principal aim of our study was to test the potential protective role of peripheral ApoJ in an experimental model of $\mathrm{AD} /$ CAA. To this end, we first considered the need to evaluate the effect of the progressive $A \beta$ deposition on cerebral endogenous mouse ApoJ levels. In fact, we confirmed that, in the APP23 mouse model, the accumulation of both insoluble $A \beta_{40}$ and $A \beta_{42}$ was accompanied by an increase in mouse ApoJ expression in the brain. This increase in ApoJ has also been described in $\mathrm{AD}$ and CAA patients [44, 45], although it is not clear whether the increase in brain ApoJ levels promotes or prevents the $A \beta$ accumulation and toxicity. In this regard, the elevated circulating levels of ApoJ observed in $\mathrm{AD}$ patients have been proposed to be a protective response against the pathologic $A \beta$ deposition [27]. To confirm this hypothesis, we treated APP23 mice with rApoJ at the time that mouse ApoJ levels elevation was not yet significant. This approach allowed us to study the efficacy of an early increase in peripheral ApoJ in terms of $A \beta$ deposition, neuronal loss, and 

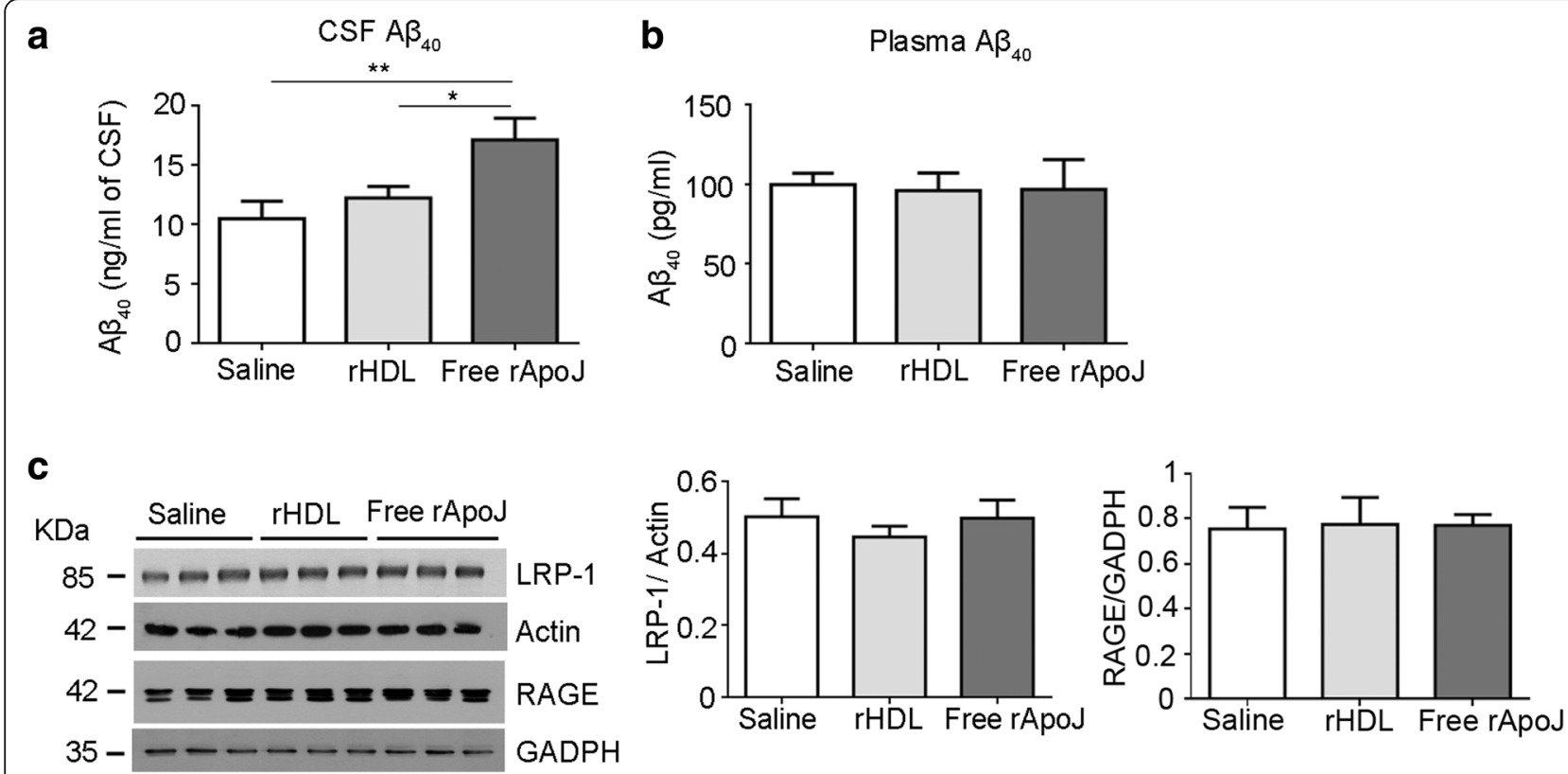

Fig. 5 Effect of $r H D L-r A p o J$ nanodiscs or free $r A p o J$ treatment on circulating $A \beta$ levels. a CSF levels of $A \beta_{40}$ detected by ELISA. b Plasmatic $A \beta_{40}$ levels detected by ELISA. c Expression of A $\beta$-transporting receptors (LRP-1 and RAGE) determined by Western blot. Data are expressed as the mean \pm SEM. $N=5-7$ group. ${ }^{*} p<0.05 ;{ }^{* *} p<0.01$

neuroinflammation. Indeed, the strategy was to increase the circulating levels of ApoJ in mice following two different treatments: intravenous administration of free rApoJ or rHDL-rApoJ nanodiscs. Several lines of evidence support the relevance of cholesterol and HDL metabolism to AD [46], and we previously observed the increased ability of rHDL-rApoJ nanodiscs to promote the efflux of cholesterol esters in vitro [34]. Therefore, we believed that the peripheral administration of rHDL-rApoJ could shed light on the effect of lipidation on the functionality of ApoJ in cerebral $\beta$-amyloidosis.

After 1 month of subchronic administration of treatments based on human rApoJ, we confirmed the presence of h-rApoJ in plasma. However, we were not able to detect h-rApoJ in the brains of mice treated with rHDL-rApoJ or free rApoJ. It has previously been described that ApoJ is able to cross the BBB [47]. Based on this, we expected that the infused rApoJ could enter the brain parenchyma, but the human protein was detected by immunofluorescence only on the luminal side of occasional leptomeningeal vessels in both rApoJ-based treatment groups. In fact, we previously observed specific vascular accumulation of rHDL-rApoJ nanodiscs in very old (28 months) APP23 mice [34]. After the corresponding subchronic peripheral treatment in APP23 mice, the cerebral $A \beta$ load was evaluated. Free rApoJ-treated mice showed significant prevention of both insoluble $A \beta_{40}$ and $A \beta_{42}$ accumulation in comparison with the saline-treated group. In turn, the treatment with rHDL-rApoJ nanodiscs resulted in the prevention of insoluble $A \beta_{42}$ accumulation. When we analyzed the distribution of $A \beta$, we observed a reduced number of $\mathrm{A} \beta$-affected vessels in both $\mathrm{rApoJ}$-based treatments. This reduction was in accordance with a previous published study [31], where authors described a marked exacerbation of CAA in APP/PS1/Clu ${ }^{-/-}$mutant mice. The authors proposed that the lack of $\mathrm{Clu}$ impaired an efficient $\mathrm{A} \beta$ clearance across the $\mathrm{BBB}$, promoting the accumulation of $A \beta$ in perivascular spaces. However, this same study showed a clear reduction of parenchymal A $\beta$ accumulation and total $\mathrm{A} \beta$ in APP/PS1 mice lacking $\mathrm{Clu}$ [31]. After this, another study showed that 5xFAD/ $\mathrm{Clu}^{-/-}$mice had less $\mathrm{A} \beta$ cerebral accumulation only in young mice, although this effect disappeared with age [32]. Beyond the valuable information obtained from these knockout models, we consider that our approach, based on the peripheral administration of rApoJ, allowed us to study the role of human ApoJ in contrast to murine ApoJ and to focus specifically on the effect of a circulating increase in ApoJ levels. As mentioned, our results obtained in aged APP23 mice treated with rApoJ partly agreed with the effect observed in the APP/PS1/ $\mathrm{Clu}^{-1-}$ mutant mice described by Wojtas et al. [31], since we detected a significant reduction in the CAA load after treatments. Thus, it can be speculated that the localization of human $\mathrm{rApoJ}$ in brain vessels after the peripheral subchronic treatment directly stimulated the clearance of $A \beta$ from perivascular drainage spaces reducing the $A \beta$ vascular load. However, we also observed that the peripheral increase of human $\mathrm{rApoJ}$ reduced the 


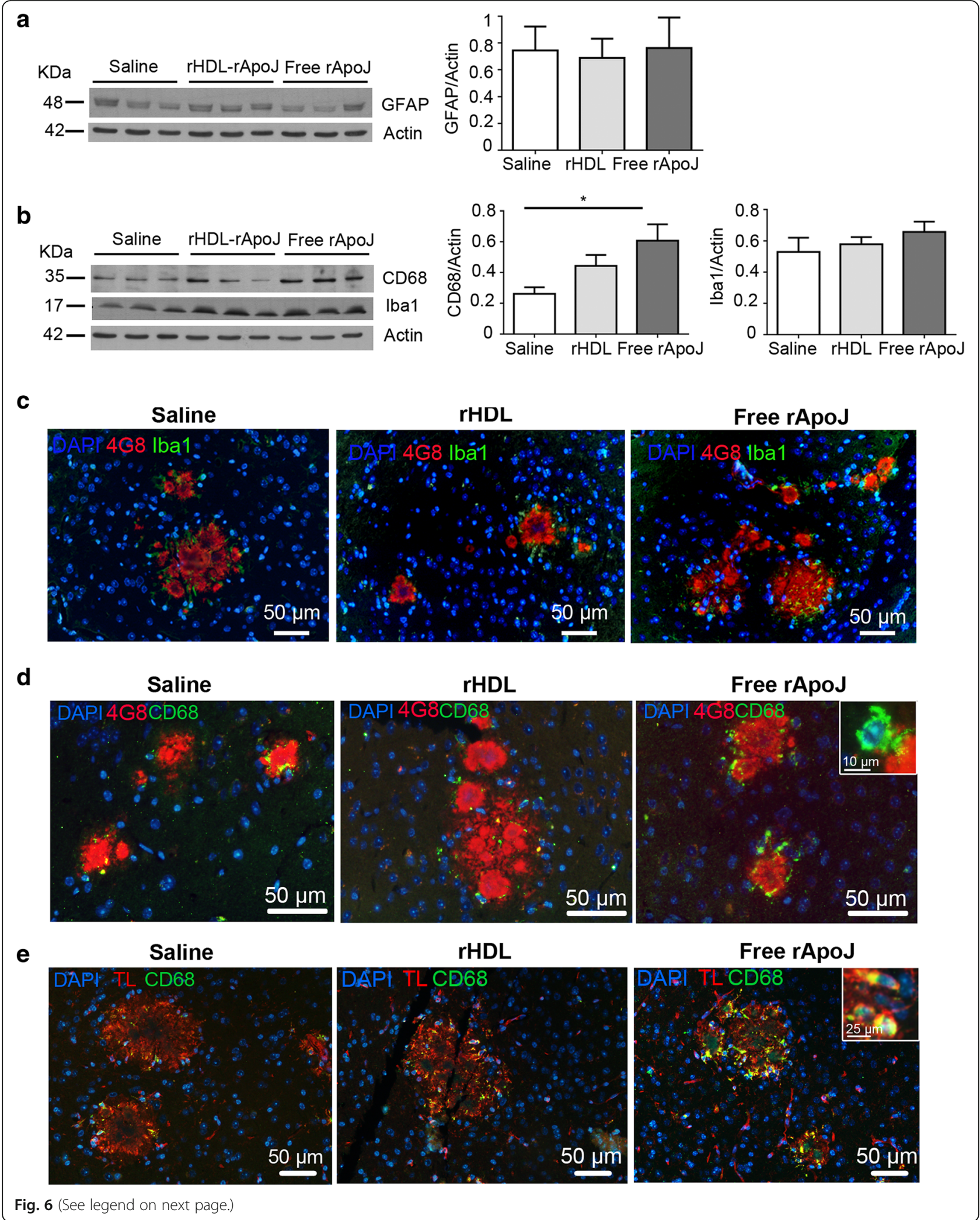


(See figure on previous page.)

Fig. 6 Levels of astrocytic and microglial markers in APP23 mice treated subchronically with saline, rHDL-rApoJ nanodiscs, or free rApoJ. a Expression of the reactive astrocyte marker GFAP in mouse APP23-brain homogenates after treatments. $\mathbf{b}$ Expression of microglial markers (CD68 and Iba-1) in mouse

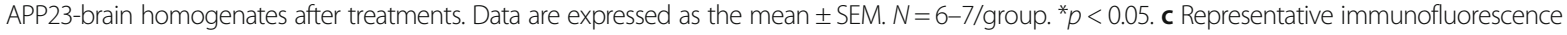
images showing the localization of Iba1 and $\mathbf{d}$ representative immunofluorescence images showing the localization of CD68 around anti-AB (4G8)-positive deposits in brain slices from APP23 mice. e Representative immunofluorescence images showing the localization of CD68 with tomato lectin (TL, as a microglial marker) in brain slices from APP23 mice

total insoluble $A \beta$ in the brain, which was accompanied by a decrease in the size of the fibrillar $A \beta$ deposits. Interestingly, these effects were observed without detecting the human rApoJ protein inside the brain. In fact, intravenous infusion of free ApoJ induced an increase in $\mathrm{A} \beta$ levels in CSF, which might reflect an $\mathrm{A} \beta$ mobilization process from the brain parenchyma. On the other hand, it has recently been proposed that intraventricular administration of an ApoJ mimetic peptide promotes the amelioration of both parenchymal and vascular $A \beta$ accumulation and improved the cognitive function if the Tg6799 mouse model [48]. These results can be understood as complementary to ours, as they focused only on the intracerebral pool of ApoJ. Therefore, to our knowledge, our study is the first to administrate human recombinant ApoJ, produced in mammalian cells, in a preclinical model of $\mathrm{AD}$. We believe that this is especially relevant due to the high structural complexity of ApoJ and the importance of its full-length form for its functionality [49].

Another beneficial effect of subchronic IV treatment with free rApoJ in APP23 mice was the prevention of neuronal loss in CA1 and poDG of the hippocampus. Due to the association between $A \beta$ deposits and neurodegeneration [50], the reduced $A \beta$ levels observed in free rApoJ-treated mice could explain the amelioration of neuronal death. Once again, as shown by the effect on A $\beta$ load after treatments, rHDL-rApoJ was less effective than the free protein, suggesting that the structural modification of ApoJ due to its lipidation may alter its ability to activate some of the protective pathways within the brain. The inflammatory state of mouse brains after ApoJ-based treatments was also determined. Treatment with free rApoJ or rHDL-ApoJ did not induce changes in the reactivity of astrocytes. Likewise, microglial proliferation was not altered among the treatment groups, but a significant increase in the expression of brain CD68 in free rApoJ-treated mice was observed. CD68 was localized surrounding $A \beta$ parenchymal deposits in cells positive for the TL dye, which stains microglia and other cells, such as macrophages and endothelial cells [40, 51]. In this context, CD68 is a lysosomal protein that has been widely used as a marker of phagocytic activity [52]. Accordingly, we demonstrated that rApoJ had a direct

Table 1 Effect of rHDL-rApoJ nanodiscs or free rApoJ on brain inflammatory status, analyzed by multiplexed ELISA. Data are expressed as the mean \pm SEM. $N=5-7 /$ group. ${ }^{*} p<0.05$ and ${ }^{* *} p<0.01$ refer to statistical differences vs. the saline-treated group determined by one-way ANOVA test (plus multiple comparison test). The false discovery rate (FDR) correction was used to control for multiple testing in the multiplexed analysis of brain inflammatory status

\begin{tabular}{|c|c|c|c|c|c|c|}
\hline $\begin{array}{l}\text { Inflammatory } \\
\text { markers }\end{array}$ & $\begin{array}{l}\text { APP23 saline } \\
(\mathrm{pg} / \mathrm{mg})\end{array}$ & $\begin{array}{l}\text { APP23 rHDL- } \\
\text { rApoJ (pg/mg) }\end{array}$ & $\begin{array}{l}\text { APP23 free } \\
\text { rApoJ (pg/mg) }\end{array}$ & $\begin{array}{l}\text { One-way ANOVA ( } 3 \\
\text { groups) } p \text { value }\end{array}$ & $\begin{array}{l}\text { rHDL-rApoJ vs saline FDR- } \\
\text { corrected } p \text { value }\end{array}$ & $\begin{array}{l}\text { Free rApoJ vs saline FDR- } \\
\text { corrected } p \text { value }\end{array}$ \\
\hline FGF-basic & $984.4 \pm 154.6$ & $895.6 \pm 113.3$ & $560.2 \pm 151.4$ & $p=0.108$ & $p=0.787$ & $p=0.174$ \\
\hline IL-1 $\beta$ & $85.28 \pm 12.17$ & $50.86 \pm 3.75$ & $72.91 \pm 11.43$ & $p=0.080$ & $p=0.122$ & $p=0.448$ \\
\hline IL2 & $151.0 \pm 13.09$ & $116.7 \pm 14.22$ & $125.2 \pm 14.49$ & $p=0.222$ & $p=0.198$ & $p=0.324$ \\
\hline IL5 & $141.7 \pm 26.35$ & $130.61 \pm 27.54$ & $148.0 \pm 21.31$ & $p=0.893$ & $p=0.819$ & $p=0.874$ \\
\hline IL6 & $203.1 \pm 22.15$ & $177.7 \pm 28.82$ & $176.3 \pm 19.5$ & $p=0.656$ & $p=0.583$ & $p=0.448$ \\
\hline IL13 & $21.31 \pm 3.40$ & $17.68 \pm 2.34$ & $12.63 \pm 3.22$ & $p=0.171$ & $p=0.552$ & $p=0.183$ \\
\hline IL17 & $20.01 \pm 2.33$ & $13.9 \pm 1.37^{*}$ & $10.23 \pm 1.08^{* *}$ & $p=0.004$ & $p=0.122$ & $p=0.017$ \\
\hline IFN- $\gamma$ & $127.8 \pm 15.53$ & $89.81 \pm 13.28$ & $94.08 \pm 10.68$ & $p=0.123$ & $p=0.137$ & $p=0.194$ \\
\hline IP10 & $54.4 \pm 4.34$ & $44.48 \pm 5.11$ & $46.71 \pm 5.05$ & $p=0.330$ & $p=0.289$ & $p=0.388$ \\
\hline KC & $1558 \pm 115.5$ & $1206 \pm 112.0^{*}$ & $1043 \pm 104.6^{* *}$ & $p=0.012$ & $p=0.122$ & $p=0.029$ \\
\hline MIG & $81.65 \pm 8.21$ & $57.81 \pm 6.91$ & $61.48 \pm 8.72$ & $p=0.090$ & $p=0.122$ & $p=0.194$ \\
\hline TNF-a & $127.2 \pm 13.46$ & $125.2 \pm 9.43$ & $144.7 \pm 17.79$ & $p=0.620$ & $p=0.937$ & $p=0.448$ \\
\hline VEGF & $17.67 \pm 2.36$ & $14.27 \pm 2.35$ & $10.72 \pm 1.22$ & $p=0.080$ & $p=0.399$ & $p=0.129$ \\
\hline MCP-1 & $36.1 \pm 3.93$ & $24.31 \pm 2.84$ & $28.19 \pm 3.12$ & $p=0.060$ & $p=0.122$ & $p=0.194$ \\
\hline
\end{tabular}


a
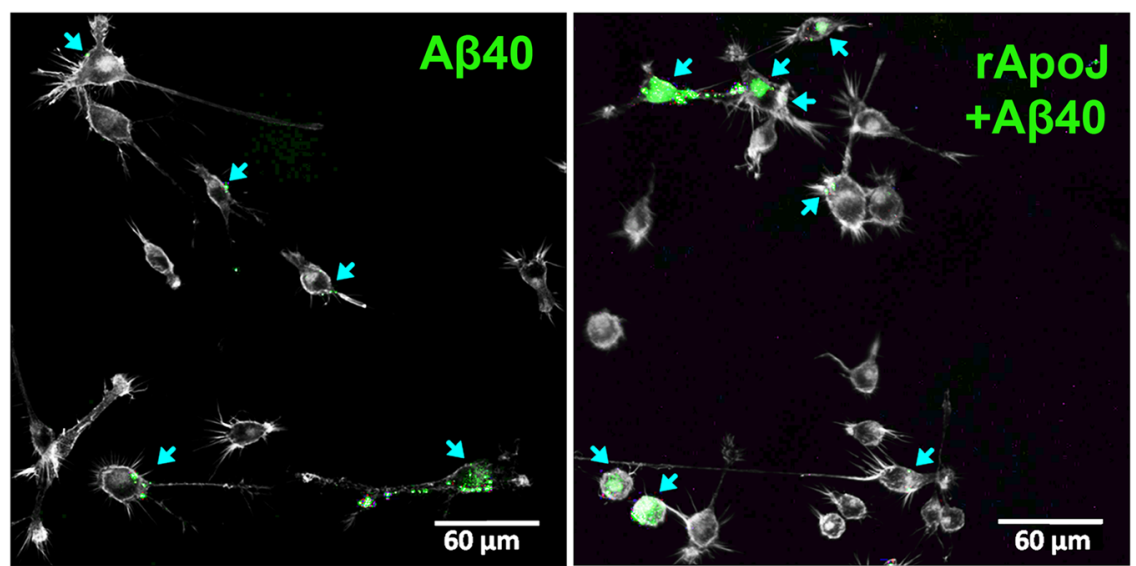

b

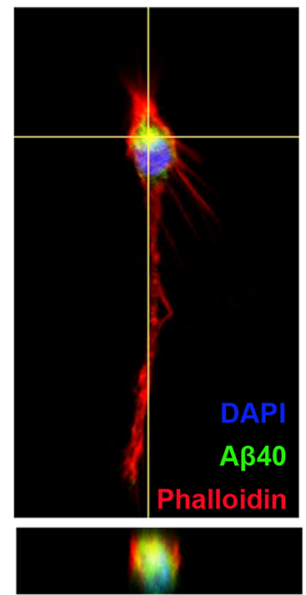

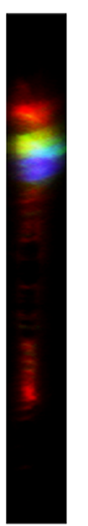

C

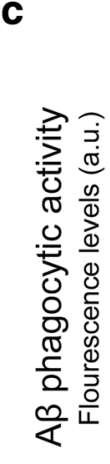

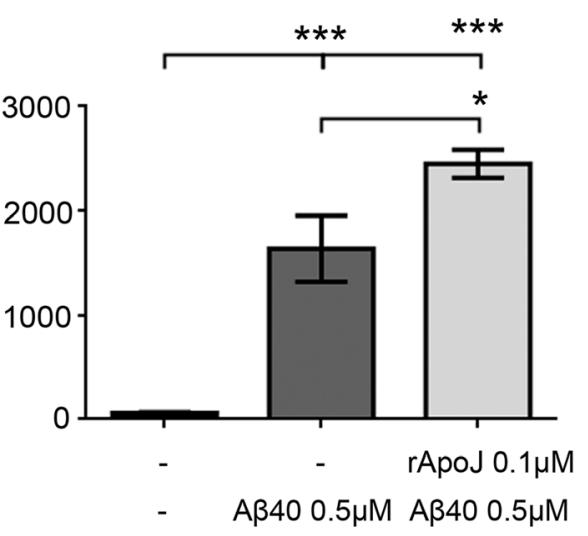

Fig. 7 Effect of rApoJ treatment on A 3 phagocytic activity of microglial cultured cells. a Representative micrographs corresponding to BV2 cells pre-incubated during $24 \mathrm{~h}$ with/without rApoJ $(0.1 \mu \mathrm{M})$ and then treated for $3 \mathrm{~h}$ with HiLyte Fluo $488-\mathrm{A} \beta 40(0.5 \mu \mathrm{M})$. Blue arrows indicate cells containing Hilyte Fluo 488-Aß40 (green). Cell morphology, visualized by TRITC-phalloidin staining, and cell nuclei with Dapi are shown in gray. b Confocal image showing the z-stack of a single cell containing HiLyte Fluo 488-Aß40 (green), stained with TRITC-phalloidin (red), and Dapi (blue). c Fluorometric quantification of HiLyte Fluo 488-A 440 in fixed BV2 cells (Ex/Em $=503 / 528 \mathrm{~nm}$ ). Data is expressed as mean \pm SEM of 4 independent experiments performed in duplicates. ${ }^{*} p<0.05$; ${ }^{* * *} p<0.001$

role enhancing the $A \beta$ uptake by microglial cells in vitro, as previously proposed [53]. However, infiltrated monocytes have previously demonstrated a higher ability than microglial cells to phagocytose A $\beta$ peptide $[14,54]$. Because resident microglia and peripheral macrophages consist of heterogeneous populations that in many ways are indistinguishable entities [55], the detailed mechanisms implicated in the stimulation of phagocytosis in brain myeloid cells by peripheral ApoJ merit exploration in future studies.

As mentioned, it has been extensively demonstrated that brain myeloid cells participate in $\mathrm{A} \beta$ elimination through phagocytosis and that stimulation of the immune response in the CNS ameliorates $A \beta$ deposition $[56,57]$. Therefore, promoting the phagocytic ability of these cell types could be a potential strategy to prevent cerebral $A \beta$ deposition. Nevertheless, the exact role of myeloid cells in pathological conditions is under discussion, since it has been observed that, for example, cultured microglia produce high levels of neurotoxic cytokines in response to $A \beta$ stimulation [58]. To test whether the enhancement of phagocytic pathways was accompanied by an increased release of inflammatory molecules, we analyzed the overall inflammatory state of brains after treatments. We did not observe an increase in the cerebral levels of classical proinflammatory molecules after treatments. In fact, reduced neuroinflammation was observed in the brains of rApoJ-treated mice in comparison with saline-treated APP23 mice, as shown by the significant reductions in IL17 and KC (the mouse homolog of CXCL1) levels, especially in free rApoJ-treated mouse brains. In this context, higher expression of IL17 has been linked to BBB disruption and neurotoxicity [59,60], and $\mathrm{KC}$ chemokine levels in the brain have been associated with memory 
deficits [61]. This last result agrees with previous studies that demonstrated anti-inflammatory and anti-apoptotic properties of ApoJ/Clu [62].

In summary, beyond the accepted implication of ApoJ in cerebral $\beta$-amyloidosis, our study is the first to demonstrate that the intravenous administration of human recombinant ApoJ is safe and effective reducing the levels of cerebral insoluble $A \beta$ and the CAA load. Indeed, our results confirm that peripheral interventions offer low invasive opportunities to regulate the cerebral $\beta$-amyloid load. An important limitation of our study is the lack of functional analysis after treatments, even though we have demonstrated that free rApoJ treatment prevents neuronal loss in the hippocampus in old APP23 mice. Further studies testing the efficacy of rApoJ treatment using different models of $\mathrm{AD}$ will be relevant to analyze its impact on behavior and cognition. We suggest that peripheral $\mathrm{rApoJ}$ promotes the amelioration of cerebral $\beta$-amyloidosis acting at the vascular level and upregulating specific phagocytic pathways in myeloid cells. However, the exact molecular pathway activated by peripheral ApoJ mediating the stimulation of the phagocytic phenotype needs to be elucidated in future studies.

\section{Additional file}

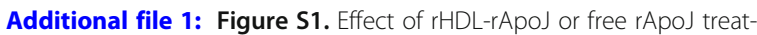
ment in the levels of mouse ApoJ in brain homogenates and plasma from treated mice, determined by ELISA. Data are expressed as the mean

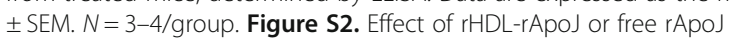
treatment in the expression of full-length APP protein and the processing of APP through $a-, \beta-$, and $\gamma$ secretases. a) Representative Western blots showing the relative amount of full-length APP, SAPPa, SAPPB, and CTFAPP. Relative quantification of b) full-length APP, c) SAPPa, d) SAPP $\beta$, and e) CTF-APP levels after treatments. Data are expressed as the mean \pm SEM. $N=6 /$ group. Table S1. List of abbreviation of tested inflammatory molecules by multiplexed ELISA. (DOCX 302 kb)

\section{Abbreviations}

AD: Alzheimer's disease; ApoE: Apolipoprotein E; ApoJ: Apolipoprotein J; APP: Amyloid precursor protein; $A \beta$ : $\beta$-Amyloid; BBB: Blood-brain barrier; BSA: Bovine serum albumin; CAA: Cerebral amyloid angiopathy; CD68: Cluster of differentiation 68; CHOL: Free cholesterol; Cholate: Sodium deoxycholate; Clu: Clusterin; CNS: Central nervous system; CSF: Cerebrospinal fluid; DAB: Diaminobenzidine; DAPI: 4',6-Diamidino-2-phenylindole; DMPC: 1,2Dimyristoyl-sn-glycero-3-phosphocholine; EDTA: Ethylenediaminetetracetic acid; ELISA: Enzyme-linked immunosorbent assay; FBS: Fetal bovine serum; FDR: False discovery rate; FLPC: Fast protein liquid chromatography; free rApoJ: Nonlipidated recombinant ApoJ; GAPDH: Glyceraldehydes 3phosphate dehydrogenase; GFAP: Glial fibrillary acidic protein; GWAS: Genome-wide association study; HDL: High-density lipoproteins; HEK293T: Human embryonic kidney 293 T cells; h-rApoJ: Human recombinant ApoJ; Iba1: Ionized calcium-binding adapter molecule-1; ICH: Intracerebral hemorrhage; IDE: Insulin-degrading enzyme; IHC: Immunohistochemistry; IL17: Interleukin 17; IL-1ß: Interleukin 1- $\beta$; IV: Intravenous; KBr: Potassium bromide; KC: Keratinocyte chemoattractant chemokine; LSD: Least significant difference; m-ApoJ: Mouse ApoJ; NEP: Neprilysin; ON: Overnight; poDG: Polymorphic layer of the dentate gyrus; px: Pixel; rHDLrApoJ: Reconstituted HDL formulated with rApoJ; RT: Room temperature; SAPPa: Soluble APP fraction-a; sAPP $\beta$ : Soluble APP fraction- $\beta$; TBS: Tris buffer saline; ThS: Thioflavin S; Thy: Thymocyte antigen-1 promoter; TL: Tomato lectin; TNF-a: Tumor necrosis factor-a; WT: Wild-type

\section{Funding}

This work has been funded by Instituto de Salud Carlos III (ISCIII) [PI17/00275, PI14/01134, and PI13/00364], co-financed by the European Regional Development Fund (FEDER), and Fundació La Marató de TV3 [40/U/2014]. The Neurovascular Research Laboratory is part of the INVICTUS+ network, ISCIII, Spain [RD16/0019/0021]. J.L.S-Q is a member of the CIBER of Diabetes and Metabolism (CIBERDEM), ISCIII, Spain. M.H-G is supported by the Miguel Servet programme, ISCIII, Spain [CPII17/00010]. ICN2 acknowledges the support of the Spanish MINECO through the Severo Ochoa Centers of Excellence Programme, under Grant SEV-2013-0295.

\section{Availability of data and materials}

The datasets used and/or analyzed during the current study are available from the corresponding author on reasonable request.

\section{Authors' contributions}

MH-G designed the study. MC-S, JM, and DM and SF-R participated in the design of the study. SF-R performed most of the experiments, collected and analyzed data, and wrote the manuscript. MS, PM, and AB participated actively in the experiments, performing $A \beta$ immunohistochemistry in mice slices and western blots. MS and $A B$ performed the microglial in vitro experiments. GC was responsible for the mice colony care. MC-S and DM designed and produced the rHDL-rApoJ nanodiscs. JLS-Q did the purification of the $\mathrm{rHDL}$ particles through $\mathrm{KBr}$ density ultracentrifugation. All authors read and approved the final manuscript.

\section{Ethics approval}

Animal use for this study was approved by the Ethics Committee for Animal Experimentation of Vall d'Hebron Research Institute (CEEA 78/13) and conducted in compliance with Spanish legislation and the Directives of the European Union.

\section{Consent for publication}

Not applicable.

\section{Competing interests}

The authors declare that they have no competing interests.

\section{Publisher's Note}

Springer Nature remains neutral with regard to jurisdictional claims in published maps and institutional affiliations.

\section{Author details}

${ }^{1}$ Neurovascular Research Laboratory, Vall d'Hebron Research Institute, Universitat Autònoma de Barcelona, 08035 Barcelona, Spain. ${ }^{2}$ Cardiovascular Biochemistry Group, Research Institute of the Hospital de Sant Pau (IIB Sant Pau), Barcelona, Spain. ${ }^{3}$ CIBER of Diabetes and Metabolism (CIBERDEM), ISCIII, Madrid, Spain. ${ }^{4}$ Catalan Institute of Nanoscience and Nanotechnology (ICN2), CSIC and the Barcelona Institute of Science and Technology, , Campus UAB, Bellaterra, Barcelona, Spain. ${ }^{5}$ Institució Catalana de Recerca i Estudis Avançats (ICREA), 08100 Barcelona, Spain.

Received: 19 December 2018 Accepted: 23 April 2019

Published online: 10 May 2019

\section{References}

1. Revesz T, Holton JL, Lashley T, Plant G, Frangione B, Rostagno A, Ghiso J. Genetics and molecular pathogenesis of sporadic and hereditary cerebral amyloid angiopathies. Acta Neuropathol. 2009;118(1):115-30.

2. Thal DR, Rüb U, Orantes M, Braak H. Phases of a beta-deposition in the human brain and its relevance for the development of AD. Neurology. 2002 58(12):1791-800

3. Wilson D, Charidimou A, Werring DJ. Advances in understanding spontaneous intracerebral hemorrhage: insights from neuroimaging. Expert Rev Neurother. 2014;14(6):661-78.

4. Reitz C, Brayne C, Mayeux R. Epidemiology of Alzheimer disease. Nat Rev Neurol. 2011;7(3):137-52

5. Attems J, Jellinger K, Thal DR, Van Nostrand W. Review: sporadic cerebral amyloid angiopathy. Neuropathol Appl Neurobiol. 2011;37(1):75-93.

6. Sinha S, Lieberburg I. Cellular mechanisms of beta-amyloid production and secretion. Proc Natl Acad Sci. 1999;96(20):11049-53. 
7. Fryer JD, Simmons K, Parsadanian M, Bales KR, Paul SM, Sullivan PM, Holtzman DM. Human apolipoprotein E4 alters the amyloid-beta 40:42 ratio and promotes the formation of cerebral amyloid angiopathy in an amyloid precursor protein transgenic model. J Neurosci. 2005;25(11):2803-10.

8. Mawuenyega KG, Sigurdson W, Ovod V, Munsell L, Kasten T, Morris JC, Yarasheski KE, Bateman RJ. Decreased clearance of CNS beta-amyloid in Alzheimer's disease. Science. 2010;330(6012):1774.

9. Jha NK, Jha SK, Kumar D, Kejriwal N, Sharma R, Ambasta RK, Kumar P. Impact of insulin degrading enzyme and neprilysin in Alzheimer's disease biology: characterization of putative cognates for therapeutic applications. J Alzheimers Dis. 2015:48(4):891-917

10. Deane R, Bell RD, Sagare A, Zlokovic BV. Clearance of amyloid-beta peptide across the blood-brain barrier: implication for therapies in Alzheimer's disease. CNS Neurol Disord Drug Targets. 2009;8(1):16-30.

11. Hawkes CA, Jayakody N, Johnston DA, Bechmann I, Carare RO. Failure of perivascular drainage of $\beta$-amyloid in cerebral amyloid angiopathy. Brain Pathol. 2014;24(4):396-403.

12. Yang CN, Shiao YJ, Shie FS, Guo BS, Chen PH, Cho CY, Chen YJ, Huang FL, Tsay HJ. Mechanism mediating oligomeric $A \beta$ clearance by naïve primary microglia. Neurobiol Dis. 2011;42(3):221-30.

13. Jones RS, Minogue AM, Connor TJ, Lynch MA. Amyloid- $\beta$-induced astrocytic phagocytosis is mediated by CD36, CD47 and RAGE. J Neurolmmune Pharmacol. 2013:8(1):301-11.

14. Simard AR, Soulet D, Gowing G, Julien JP, Rivest S. Bone marrow-derived microglia play a critical role in restricting senile plaque formation in Alzheimer's disease. Neuron. 2006;49(4):489-502.

15. Salter MW, Stevens B. Microglia emerge as central players in brain disease. Nat Med. 2017;23(9):1018-27.

16. Nicoll JAR, McCarron MO. APOE gene polymorphism as a risk factor for cerebral amyloid angiopathy-related hemorrhage. Amyloid. 2001;8(Suppl 1):51-5.

17. Strittmatter WJ, Saunders AM, Schmechel D, Pericak-Vance M, Enghild J, Salvesen GS, Roses AD. Apolipoprotein E: high-avidity binding to betaamyloid and increased frequency of type 4 allele in late-onset familial Alzheimer disease. Proc Natl Acad Sci U S A. 1993:90(5):1977-81.

18. DeMattos RB, Cirrito JR, Parsadanian M, May PC, O'Dell MA, Taylor JW, Harmony JA, Aronow BJ, Bales KR, Paul SM, Holtzman DM. ApoE and clusterin cooperatively suppress Abeta levels and deposition: evidence that ApoE regulates extracellular Abeta metabolism in vivo. Neuron. 2004:41(2): 193-202.

19. Kim J, Basak JM, Holtzman DM. The role of apolipoprotein E in Alzheimer's disease. Neuron. 2009;63(3):287-303.

20. DeMattos RB, Brendza RP, Heuser JE, Kierson M, Cirrito JR, Fryer J, Sullivan PM, Fagan AM, Han X, Holtzman DM. Purification and characterization of astrocyte-secreted apolipoprotein $\mathrm{E}$ and J-containing lipoproteins from wild-type and human apoE transgenic mice. Neurochem Int. 2001:39(5-6): 415-25

21. Schwarz M, Spath L, Lux CA, Paprotka K, Torzewski M, Dersch K, Koch-Brandt C, Husmann M, Bhakdi S. Potential protective role of apoprotein J (clusterin) in atherogenesis: binding to enzymatically modified low-density lipoprotein reduces fatty acid-mediated cytotoxicity. Thromb Haemost. 2008;100(1):110-8.

22. Song HB, Jun HO, Kim JH, Yu YS, Kim KW, Min BH, Kim JH. Anti-apoptotic effect of clusterin on cisplatin-induced cell death of retinoblastoma cells. Oncol Rep. 2013;30(6):2713-8.

23. McDonald JF, Nelsestuen GL. Potent inhibition of terminal complement assembly by clusterin: characterization of its impact on C9 polymerization. Biochemistry. 1997;36(24):7464-73.

24. Beeg M, Stravalaci M, Romeo M, Carrá AD, Cagnotto A, Rossi A, Diomede L, Salmona M, Gobbi M. Clusterin binds to A 1-42 oligomers with high affinity and interferes with peptide aggregation by inhibiting primary and secondary nucleation. J Biol Chem. 2016:291(13):6958-66.

25. Yerbury JJ, Poon S, Meehan S, Thompson B, Kumita JR, Dobson CM, Wilson MR. The extracellular chaperone clusterin influences amyloid formation and toxicity by interacting with prefibrillar structures. FASEB J. 2007;21(10):2312-22.

26. Howlett DR, Hortobágyi T, Francis PT. Clusterin associates specifically with A 440 in Alzheimer's disease brain tissue. Brain Pathol. 2013;23(6):623-32.

27. Lambert J-C, Heath S, Even G, Campion D, Sleegers K, Hiltunen M, Combarros O, Zelenika D, Bullido MJ, Tavernier B, Letenneur L, Bettens K, Berr C, Pasquier F, Fiévet N, Barberger-gateau P, Engelborghs S, De Deyn P, Mateo I, Franck A, Helisalmi S, Porcellini E, Hanon O, European Alzheimer's Disease. Initiative Investigators, de Pancorbo MM, Lendon C, Dufouil C, Jaillard C, Leveillard T, Alvarez V, Bosco P, Mancuso M, Panza F, Nacmias B,
Bossù P, Piccardi P, Annoni G, Seripa D, Galimberti D, Hannequin D, Licastro F, Soininen H, Ritchie K, Blanché H, Dartigues JF, Tzourio C, Gut I, Van Broeckhoven C, Alpérovitch A, Lathrop M, Amouyel P. Genome-wide association study identifies variants at CLU and CR1 associated with Alzheimer's disease. Nat Genet. 2009;41(10):1094-9.

28. Nelson AR, Sagare AP, Zlokovic BV. Role of clusterin in the brain vascular clearance of amyloid- $\beta$. Proc Natl Acad Sci U S A. 2017;114(33):8681-2.

29. Schrijvers EMC, Koudstaal PJ, Hofman A, Breteler MMB. Plasma clusterin and the risk of Alzheimer disease. JAMA. 2011;305:1322-6.

30. DeMattos RB, O'dell MA, Parsadanian M, Taylor JW, Harmony JA, Bales KR, Paul SM, Aronow BJ, Holtzman DM. Clusterin promotes amyloid plaque formation and is critical for neuritic toxicity in a mouse model of Alzheimer's disease. Proc Natl Acad Sci U S A. 2002:99(16):10843-8.

31. Wojtas AM, Kang SS, Olley BM, Gatherer M, Shinohara M, Lozano PA, Liu CC, Kurti A, Baker KE, Dickson DW, Yue M, Petrucelli L, Bu G, Carare RO, Fryer JD. Loss of clusterin shifts amyloid deposition to the cerebrovasculature via disruption of perivascular drainage pathways. Proc Natl Acad Sci U S A. 2017; 114(33):E6962-71

32. Oh SB, Kim MS, Park S, Son H, Kim SY, Kim MS, Jo DG, Tak E, Lee JY. Clusterin contributes to early stage of Alzheimer's disease pathogenesis. Brain Pathol. 2018. https://doi.org/10.1111/bpa.12660

33. de Silva HV, Stuart WD, Duvic CR, Wetterau JR, Ray MJ, Ferguson DG, Albers HW, Smith WR, Harmony JA. A 70-kDa apolipoprotein designated ApoJ is a marker for subclasses of human plasma high density lipoproteins. J Biol Chem. 1990;265(22):13240-7.

34. Fernández-De-Retana S, Cano-Sarabia M, Marazuela $P$, Sánchez-Quesada JL, Garcia-Leon A, Montañola A, Montaner J, Maspoch D, Hernández-Guillamon M. Characterization of ApoJ-reconstituted high-density lipoprotein ( $\mathrm{rHDL}$ ) nanodisc for the potential treatment of cerebral $\beta$-amyloidosis. Sci Rep. 2017;7(1):14637.

35. Merino-Zamorano C, Fernández-de Retana S, Montañola A, Batlle A, Saint-Pol J, Mysiorek C, Gosselet F, Montaner J, Hernández-Guillamon M. Modulation of amyloid- $\beta 1-40$ transport by ApoA1 and ApoJ across an in vitro model of the blood-brain barrier. J Alzheimers Dis. 2016;53(2):677-91.

36. Sturchler-Pierrat C, Staufenbiel M. Pathogenic mechanisms of Alzheimer's disease analyzed in the APP23 transgenic mouse model. Ann N Y Acad Sci. 2000;920:134-9.

37. Yardeni T, Eckhaus M, Morris HD, Huizing M, Hoogstraten-Miller S. Retroorbital injections in mice. Lab Anim (NY). 2011;40(5):155-60.

38. Liu L, Duff K. A technique for serial collection of cerebrospinal fluid from the cisterna magna in mouse. J Vis Exp. 2008;10(21). https://doi.org/10.3791/960.

39. Shang J, Yamashita T, Zhai Y, Nakano Y, Morihara R, Fukui Y, Hishikawa N, Ohta $Y$, Abe K. Strong impact of chronic cerebral hypoperfusion on neurovascular unit, cerebrovascular remodeling, and neurovascular trophic coupling in Alzheimer's disease model mouse. J Alzheimers Dis. 2016:52(1):113-26.

40. Villacampa N, Almolda B, González B, Castellano B. Tomato lectin histochemistry for microglial visualization. Methods Mol Biol. 2013;1041:261-79.

41. Grignon Y, Duyckaerts C, Bennecib M, Hauw J-J. Cytoarchitectonic alterations in the supramarginal gyrus of late onset Alzheimer's disease. Acta Neuropathol. 1998;95(4):395-406.

42. Mattsson N, Lönneborg A, Boccardi M, Blennow K, Hansson O. Geneva task force for the roadmap of Alzheimer's biomarkers. Clinical validity of cerebrospinal fluid A 342 , tau, and phospho-tau as biomarkers for Alzheimer's disease in the context of a structured 5-phase development framework. Neurobiol Aging. 2017;52:196-213.

43. Van Etten ES, Verbeek MM, Van Der Grond J, Zielman R, van Rooden S, van Zwet EW, van Opstal AM, Haan J, Greenberg SM, van Buchem MA, Wermer MJ, Terwindt GM. $\beta$-Amyloid in CSF: biomarker for preclinical cerebral amyloid angiopathy. Neurology. 2017:88(2):169-76.

44. Oda T, Pasinetti GM, Osterburg HH, Anderson C, Johnson SA, Finch CE. Purification and characterization of brain clusterin. Biochem Biophys Res Commun. 1994;204(3):1131-6.

45. Miners JS, Clarke P, Love S. Clusterin levels are increased in Alzheimer's disease and influence the regional distribution of A 3 . Brain Pathol. 2017 27(3):305-13.

46. Reitz C, Tang M-X, Schupf N, Manly JJ, Mayeux R, Luchsinger JA. Association of higher levels of high-density lipoprotein cholesterol in elderly individuals and lower risk of late-onset Alzheimer disease. Arch Neurol. 2010;67(12): 1491-7.

47. Zlokovic BV, Martel CL, Mackic JB, Matsubara E, Wisniewski T, McComb JG Frangione B, Ghiso J. Brain uptake of circulating apolipoproteins J and E 
complexed to Alzheimer's amyloid beta. Biochem Biophys Res Commun. 1994;205(2):1431-7.

48. Qi XM, Wang C, Chu XK, Li G, Ma JF. Intraventricular infusion of clusterin ameliorated cognition and pathology in Tg6799 model of Alzheimer's disease. BMC Neurosci. 2018;19(1):2. https:/doi.org/10.1186/s12868-018-0402-7.

49. Dabbs RA, Wilson MR. Expression and purification of chaperone-active recombinant clusterin. PLoS One. 2014;9(1):e86989.

50. Calhoun ME, Wiederhold KH, Abramowski D, Phinney AL, Probst A, Sturchler-Pierrat C, Staufenbiel M, Sommer B, Jucker M. Neuron loss in APP transgenic mice. Nature. 1998;395(6704):755-6.

51. Andjelkovic AV, Nikolic B, Pachter JS, Zecevic N. Macrophages/microglial cells in human central nervous system during development: an immunohistochemical study. Brain Res. 1998:814(1-2):13-25.

52. Hoogland ICM, Houbolt C, van Westerloo DJ, van Gool WA, van de Beek D. Systemic inflammation and microglial activation: systematic review of animal experiments. J Neuroinflammation. 2015;12:114.

53. Yeh FL, Wang Y, Tom I, Gonzalez LC, Sheng M. TREM2 binds to apolipoproteins, including APOE and CLU/APOJ, and thereby facilitates uptake of amyloid-beta by microglia. Neuron. 2016;91(2):328-40

54. Malm T, Koistinaho M, Muona A, Magga J, Koistinaho J. The role and therapeutic potential of monocytic cells in Alzheimer's disease. Glia. 2010; 58(8):889-900.

55. Lai AY, McLaurin J. Clearance of amyloid- $\beta$ peptides by microglia and macrophages: the issue of what, when and where. Future Neurol. 2012;7(2): $165-76$.

56. Michaud J-P, Hallé $M$, Lampron $A$, Thériault $P$, Préfontaine $P$, Filali $M$, Tribout-Jover P, Lanteigne AM, Jodoin R, Cluff C, Brichard V, Palmantier R, Pilorget $\mathrm{A}$, Larocque $\mathrm{D}$, Rivest $\mathrm{S}$. Toll-like receptor 4 stimulation with the detoxified ligand monophosphoryl lipid A improves Alzheimer's diseaserelated pathology. Proc Natl Acad Sci U S A. 2013;110(5):1941-6.

57. Yamanaka M, Ishikawa T, Griep A, Axt D, Kummer MP, Heneka MT. PPARy/ RXRa-induced and CD36-mediated microglial amyloid- $\beta$ phagocytosis results in cognitive improvement in amyloid precursor protein/presenilin 1 mice. J Neurosci. 2012;32(48):17321-31.

58. Kim SU, de Vellis J. Microglia in health and disease. J Neurosci Res. 2005; 81(3):302-13.

59. Zenaro E, Pietronigro E, Della Bianca V, Piacentino G, Marongiu L, Budui S, Turano E, Rossi B, Angiari S, Dusi S, Montresor A, Carlucci T, Nanì S, Tosadori G, Calciano L, Catalucci D, Berton G, Bonetti B, Constantin G, Piacentino G, Marongiu L, Budui S, Turano E, Rossi B, Angiari S, Dusi S, Montresor A, Carlucci T, Nanì S, Tosadori G, Calciano L, Catalucci D, Berton G, Bonetti B, Constantin G. Neutrophils promote Alzheimer's disease-like pathology and cognitive decline via LFA-1 integrin. Nat Med. 2015;21(8):880-6.

60. Kebir H, Kreymborg K, Ifergan I, Dodelet-Devillers A, Cayrol R, Bernard M, Giuliani F, Arbour N, Becher B, Prat A. Human TH17 lymphocytes promote blood-brain barrier disruption and central nervous system inflammation. Nat Med. 2007;13(10):1173-5

61. Silva B, Sousa L, Miranda A, Vasconcelos A, Reis H, Barcelos L, Arantes R, Teixeira A, Rachid MA. Memory deficit associated with increased brain proinflammatory cytokine levels and neurodegeneration in acute ischemic stroke. Arq Neuropsiquiatr. 2015;73(8):655-9.

62. Cunin P, Beauvillain C, Miot C, Augusto JF, Preisser L, Blanchard S, Pignon P, Scotet M, Garo E, Fremaux I, Chevailler A, Subra JF, Blanco P, Wilson MR, Jeannin P, Delneste Y. Clusterin facilitates apoptotic cell clearance and prevents apoptotic cell-induced autoimmune responses. Cell Death Dis. 2016;: :2215.

Ready to submit your research? Choose BMC and benefit from:

- fast, convenient online submission

- thorough peer review by experienced researchers in your field

- rapid publication on acceptance

- support for research data, including large and complex data types

- gold Open Access which fosters wider collaboration and increased citations

- maximum visibility for your research: over $100 \mathrm{M}$ website views per year

At BMC, research is always in progress.

Learn more biomedcentral.com/submissions 